\title{
Beauty is skin deep: the skin tones of Vermeer's Girl with a Pearl Earring
}

\author{
Annelies van Loon ${ }^{1,2^{*}}$ (], Abbie Vandivere ${ }^{1}$, John K. Delaney ${ }^{3}$, Kathryn A. Dooley ${ }^{3}$, Steven De Meyer ${ }^{4}$, \\ Frederik Vanmeert ${ }^{4}$, Victor Gonzalez ${ }^{2}$, Koen Janssens ${ }^{4}$, Emilien Leonhardt ${ }^{5}$, Ralph Haswell ${ }^{6}$, Suzan de Groot ${ }^{7}$, \\ Paolo D'Imporzano ${ }^{8}$ and Gareth R. Davies ${ }^{8}$
}

\begin{abstract}
The soft modelling of the skin tones in Vermeer's Girl with a Pearl Earring (Mauritshuis) has been remarked upon by art historians, and is their main argument to date this painting to c. 1665. This paper describes the materials and techniques Vermeer used to accomplish the smooth flesh tones and facial features of the Girl, which were investigated as part of the 2018 Girl in the Spotlight research project. It combines macroscopic X-ray fluorescence imaging (MA-XRF), reflectance imaging spectroscopy (RIS), and 3D digital microscopy. Vermeer built up the face, beginning with distinct areas of light and dark. He then smoothly blended the final layers to create almost seamless transitions. The combination of advanced imaging techniques highlighted that Vermeer built the soft contour around her face by leaving a 'gap' between the background and the skin. It also revealed details that were otherwise not visible with the naked eye, such as the eyelashes. Macroscopic imaging was complemented by the study of paint cross-sections using: light microscopy, SEM-EDX, FIB-STEM, synchrotron radiation $\mu$-XRPD and FTIR-ATR. Vermeer intentionally used different qualities or grades of lead white in the flesh paints, showing different hydrocerussite/cerussite ratios and particle sizes. Lead isotope analysis showed that the geographic source of lead, from which the different types of lead white were manufactured, was the same: the region of Peak District of Derbyshire, UK. Finally, cross-section analysis identified the formation of new lead species in the paints: lead soaps and palmierite $\left(\mathrm{K}_{2} \mathrm{~Pb}\left(\mathrm{SO}_{4}\right)_{2}\right)$, associated with the red lake.
\end{abstract}

Keywords: Painting technique 17th century, Flesh paint, Contours, Lead white, Lead isotopes, Lead degradation products, Advanced imaging techniques, Paint cross-sections

\section{Introduction}

The idealised figure in Johannes Vermeer's Girl with a Pearl Earring (c. 1665, Mauritshuis, the Netherlands, Fig. 1a) conveys a sense of timeless beauty. The painting does not depict a specific person, but was intended as a tronie: a character study of a girl dressed in exotic costume [1]. Her skin is soft and smooth, with an impeccable transition from light to dark from one side of her face to the other. The softening of transitions and contours in the face, rather than using sharp lines and definitions, creates the effect of sfumato (after Leonardo da Vinci) [2,

\footnotetext{
*Correspondence: a.van.loon@rijksmuseum.nl

${ }^{1}$ Conservation Department, Mauritshuis, Plein 29, 2511 CS The Hague, The Netherlands

Full list of author information is available at the end of the article
}

3]. In contrast to the face, the headdress and jacket are painted in a more free and spontaneous manner. The Girl is silhouetted against a dark background, which makes her face appear lighter, enhancing the three-dimensional effect of the composition [4]. Girl with a Pearl Earring holds a special place in Vermeer's oeuvre, which for the most part is comprised of domestic interior scenes. The only other painting in which he depicted a single female half-figure against a dark background is Study of a Young Woman (c. 1665-1667, The Metropolitan Museum of Art, New York). These works are of a similar size, were almost certainly painted at around the same time, and are both considered to be tronies [5]. Vermeer developed the techniques to render soft flesh tones around 1665, in paintings such as Woman Holding a Balance (c. 1664,

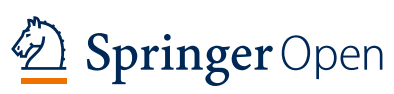

(c) The Author(s) 2019. This article is distributed under the terms of the Creative Commons Attribution 4.0 International License (http:// creativecommons.org/licenses/by/4.0/), which permits unrestricted use, distribution, and reproduction in any medium, provided you give appropriate credit to the original author(s) and the source, provide a link to the Creative Commons license, and indicate if changes were made. The Creative Commons Public Domain Dedication waiver (http://creativecommons.org/publicdomain/zero/1.0/) applies to the data made available in this article, unless otherwise stated. 

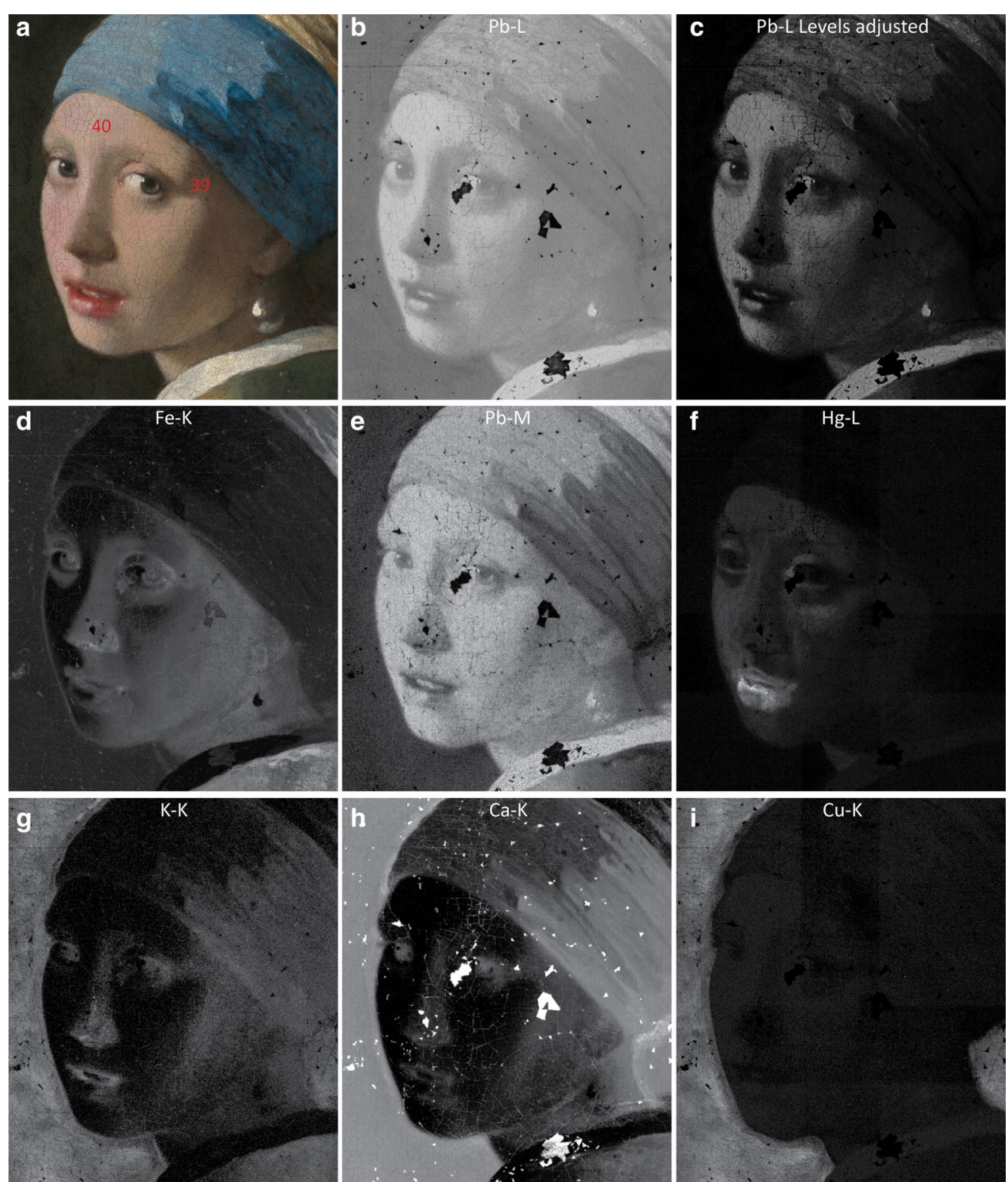

Fig. 1 Detail of Johannes Vermeer, Girl with a Pearl Earring, c. 1665, oil on canvas, Mauritshuis, The Hague (inv nr 670), showing the face of the Girl and sample locations 39 and 40. a Visible light image. René Gerritsen Art \& Research Photography. Corresponding MA-XRF maps (0.4 mm/pixel): b, c lead (Pb-L), $\mathbf{d}$ iron, e lead (Pb-M), $\mathbf{f}$ mercury, $\mathbf{g}$ potassium, $\mathbf{h}$ calcium, $\mathbf{i}$ copper

National Gallery of Art, Washington) and Young Woman with a Water Pitcher (c. 1662, The Metropolitan Museum of Art, New York) [6]. The soft modelling is also the main argument to date the Mauritshuis' Girl with a Pearl Earring to c. 1665 [3].

Vermeer exploited the 'turbid medium effect' (bluehued scattering) to create cool midtones. Applying a thin light paint layer on top of a warm dark underpaint, so that the underlayer remains somewhat visible, makes the upper layers appear cooler in tone: the shorter (blue) wavelengths are reflected by the lead white particles, while the longer (red) wavelengths penetrate deeper in the layer structure and are absorbed by the dark underpaint $[7,8]$. In his later paintings, Vermeer seems to have changed his approach, using a technique that sets him apart from his Dutch contemporaries. He applied paint containing the pigment green earth on top of the other flesh colours to create shadows in the skin tones [7, 9]. Gifford and Glinsman reported the use of green earth in at 
least fifteen of his works, mainly in the skin tones [10]. Girl with a Pearl Earring appears to conform more closely to the techniques used in the 1660s, rather than his later works.

This paper investigates the techniques and materials Vermeer used to construct the soft flesh tones and facial features in Girl with a Pearl Earring. The 2018 Girl in the Spotlight research project involved in-depth technical examination of the painting using advanced imaging techniques, since its last treatment in 1994 [11]. Results are presented from macroscopic $\mathrm{X}$-ray fluorescence scanning (MA-XRF), visible and near-infrared reflectance imaging spectroscopy (RIS), as well as three-dimensional digital microscopy. MAXRF analysed the chemical elements in the paint, in both surface and subsurface layers, from which the pigments could be inferred [12]. RIS is complementary to MA-XRF, and provided molecular information about pigments. The main body of RIS results is topic of another article in this series [13]. 3D digital microscopy imaged the entire painting at $35 \times$ magnification, resulting in c. 9000 tiles that were stitched together providing a visual image of $4.4 \mu \mathrm{m} /$ pixel size (almost $6000 \mathrm{dpi})$.

To complement the results from macroscale imaging, and because no clear samples had been taken from the skin in the 1990s [14], the opportunity was taken to sample the flesh tones. One sample was collected from a pink highlight, and one from a shadow of the skin (Fig. 1a). These were prepared as paint crosssections, and examined using multiple analytical techniques: scanning electron microscopy combined with energy dispersive X-ray analysis (SEM-EDX), focused ion beam-scanning transmission electron microscopy (FIB-STEM), synchrotron radiation microscopic X-ray powder diffraction ( $\mu$-XRPD), Fourier transform infrared-attenuated total reflectance spectroscopy (FTIRATR), and lead isotope analysis. This yielded new information about the stratigraphy and thickness of the layers at discrete locations, and confirmed the presence of pigments inferred from MA-XRF. It also allowed a deeper analysis of the lead white pigment used in the underlayers and surface layers. The XRPD analyses of the different types of lead white, carried out as part of the 2018 Girl in the Spotlight research, are published elsewhere [15]. These are briefly summarised in this paper, and presented together with new information from SEM-EDX, FTIR-ATR and lead isotope analysis. This provided new insights into Vermeer's intentional use of different types of lead white in the skin tones. Finally, FIB-STEM and FTIR-ATR revealed the formation of new lead species, as a result of aging and degradation of the paint, which has consequences for the present appearance of the Girl's face.

\section{Stack process lead white (Dutch method)}

Seventeenth-century Dutch artists typically used stack process lead white. During its manufacture, strips of metallic lead were placed over weak acetic acid (vinegar) in porous earthenware pots. Several pots were stored in sheds and covered with fermenting (horse) manure, which produces heat and carbon dioxide $\left(\mathrm{CO}_{2}\right)$ [16]. The stack process leads to the formation of a lead white pigment containing hydrocerussite ( $\mathrm{HC}$, basic lead carbonate: $\left.\mathrm{Pb}_{3}\left(\mathrm{CO}_{3}\right)_{2}(\mathrm{OH})_{2}\right)$ and cerussite (C, neutral lead carbonate: $\mathrm{PbCO}_{3}$ ) in a $\mathrm{HC}: \mathrm{C}$ weight ratio between $60: 40$ and 80:20 [17]. Changing the synthesis conditions, such as corrosion time or extra supply of $\mathrm{CO}_{2}$, could shift this ratio towards a higher hydrocerussite or cerussite quantity. The raw material was usually post-processed by paint manufactures or painters themselves-for example, by washing or heating the pigment in water or vinegar-to obtain different grades or qualities of lead white [18]. Heating in water can account for large-sized crystallites and an increase of hydrocerussite $[17,18]$. Conversely, washing in vinegar can lead to smaller particles and more cerussite. A third post-processing method, levigation, was also used to select only the finest pigment particles. Experiments with levigation of lead white showed that the fraction of finest particles, obtained by decanting, contains more cerussite than the coarser fractions $[19,20]$. Both variations in the crystalline ratios of $\mathrm{HC}$ and $\mathrm{C}$ and particle size influence the optical and handling properties of the lead white paint when mixed in oil [21-23].

\section{Lead isotope analysis}

The isotopic composition of lead in the lead white pigment can potentially provide more information about where or how Vermeer obtained the various qualities of lead white that he used to paint the Girl's face. Natural lead occurs as a combination of four stable isotopes: ${ }^{204} \mathrm{~Pb},{ }^{206} \mathrm{~Pb},{ }^{207} \mathrm{~Pb}$, and ${ }^{208} \mathrm{~Pb}$. The timeframe and geochemical conditions under which the ore is formed determine the lead isotope composition of a lead-containing mineral [24]. This makes it possible to trace the source of the lead back to the mine where the ore was extracted, based on the lead isotope ratio. Although within Europe, some mines have overlapping isotopic compositions-as is the case for some British, German and Polish mines-lead isotope analysis can easily distinguish between Flemish and Italian lead white [25]. 


\section{Results and discussion}

\section{Building up the skin tones}

Building up the three-dimensionality of the face using underlayers

Vermeer achieved convincing three-dimensionality in the Girl's face by having the left (her proper right) side facing the light and the right (her proper left) side in shadow. There is an imperceptible transition between the two sides of the face, which follows her cheekbone. Cool midtones define her features, especially around her eyes, and on the side of her nose. He built up the skin tones of Girl with a Pearl Earring in several distinct phases, presumably leaving them to dry between each step.

The paint surface was examined using a stereomicroscope at $40 \times$ magnification. Stereomicroscopy showed that the lit parts of her face (on the left) were underpainted with a cream-coloured underlayer, which was thickly applied to also create physical three-dimensionality. On top, Vermeer applied a vivid pink surface layer. For the cool midtones, including the areas around her eyes, he used a greyish or brown underlayer, on top of which he applied a thin flesh paint with a lighter colour. The darker shadows, for example the zigzag-shaped shadow on her cheek and the underside of her nose, are underpainted with a reddish brown. The shadow areas are finished with a thin flesh paint, comparable in colour to the midtones, but even thinner. The recent observations are in accordance with observations made during the 1994 restoration treatment [7]. Over time, the upper paint layers in the Girl's skin have become partially abraded, and the underlayers have been partially revealed. Many of the damages were retouched as part of the 1994 treatment [26].

MA-XRF is capable of visualising the presence of lead in both surface and underlayers. The $\mathrm{Pb}-\mathrm{L}$ signal is the higher energetic emission line of lead, therefore its distribution map can contain contributions from deeper within the paint structure. The distribution of lead white in the lower layers of her face was difficult to visualise because of the contribution of the lead white from the ground (Fig. 1b). To improve legibility, the lead (Pb-L) map was digitally adjusted by changing the 'levels' in Photoshop (Fig. 1c). The lead (Pb-L) map shows a strong contrast between the left (lit) side of the Girl's face-which shows a high $\mathrm{Pb}-\mathrm{L}$ signal, and the right (shadow) sidewhich shows a low Pb-L signal. The iron map, on the other hand, shows higher iron signals in the shadow areas around her eyes, in her nose, cheek and neck (Fig. 1d).

The lead $(\mathrm{Pb}-\mathrm{M})$ map is from the lower energetic emission line of lead, and is usually dominated by lead present in the surface layers (Fig. 1e). Here, it reveals the omnipresence of lead white in all surface paint layers of the flesh: light, mid- and shadow tones. The MA-XRF maps for lead $(\mathrm{Pb}-\mathrm{M})$ and mercury $(\mathrm{Hg}-\mathrm{L})$ indicate that the pink flesh tones on the left (lit) side of the face contain both lead white and vermilion (Fig. 1e, f). The thin surface layers used in the upper layers of the mid- and shadow tones contain earth pigments, lead white and only a tiny bit of vermilion, as inferred from the MA-XRF maps of iron (Fe-K), lead (Pb-M), and mercury (Hg-L) (Fig. 1d, e, f). The shadow areas correlate with the light (high intensity) areas of the MA-XRF map for potassium $(\mathrm{K}-\mathrm{K})$, and also appear to contain some calcium (Ca-K) (Fig. 1g, h). Both potassium and calcium can be associated with substrates of an organic lake [27, 28].

In the visible light image, the transition between light and shadow in the Girl's face seems flawless and gradual, but evidence from MA-XRF confirms that light, midtone and shadow were underpainted and finished with different paints. The different colour areas appear to be more clearly defined in the MA-XRF maps. This shows that from an early stage of painting, Vermeer had a clear idea of how he wanted to depict the fall of light and shade on the face, and built each area up systematically using underlayers with different colours. Gifford pointed out that "Vermeer's first layers were not simply a compositional guide, but that from the start he used it to establish the play of light as a central element describing the composition" [29]. The underlayers of the Girl's face show a stronger light-dark contrast-varying from a light cream colour for the light areas to a reddish brown for the deeper shadows-than is visible in the final image. Vermeer even created a physical three-dimensionality by applying the light cream-coloured underlayer(s) more thickly beneath the light parts of her face.

\section{Upper paint layers: blending and highlighting}

Once the underlayers were dry, Vermeer applied the smooth final paint layers on top and varied their thickness and composition. In the lit part of the face, the upper layer is relatively thick. In contrast, the midtones and shadows reveal very thin applications of final paint applied as a scumble, so that the underlayer was left partially exposed and played a role in the final colour.

A detail of the Girl's cheek shows the smooth blending between three different pinkish-brown flesh tones, from light (Fig. 2a: region 1) to cool midtone (Fig. 2a: region 2) to shadow (Fig. 2a: region 3). The blending between these areas is so subtle that Vermeer's process for applying the upper layers is difficult to visualise. Presumably Vermeer softly dragged the (slightly) wet paint from one area to another with a dry brush, creating an almost seamless transition from highlight to shadow. During the 1994 treatment, small hairs-presumably from Vermeer's brush-were found in the flesh paint, especially in 

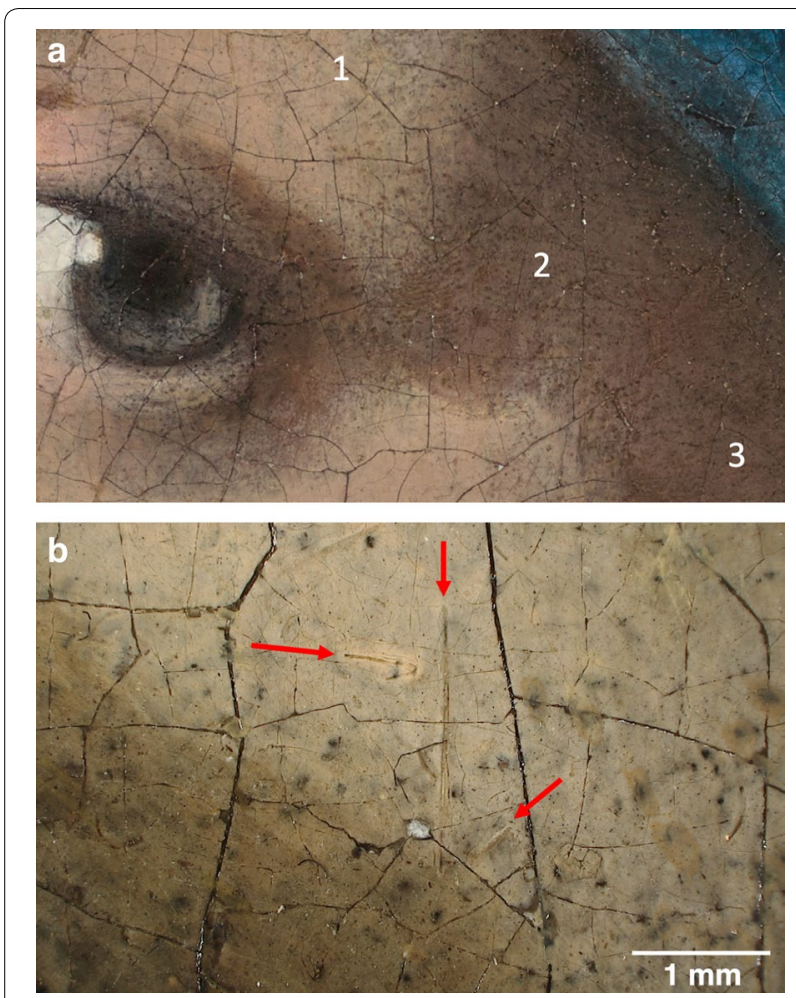

Fig. 2 a Polarised light image, showing the soft transitions in the Girl's cheek: 1: light skin tone, 2: cool midtone, 3: shadow. René Gerritsen Art \& Research Photography. b 3D digital micrograph of the Girl's cheek showing small hairs embedded in the paint (some indicated with red arrows)

the midtone areas that required a soft modelling [1]. The hairs are visible in the high-resolution 3D digital micrographs (Fig. 2b). This supports the idea that Vermeer blended his paint with a dry brush, and some of the hairs broke off.

The above shows that Vermeer created the subtle transitions by carefully blending the final paint layers. He varied the thickness of the final paint layers, making use of dark(er) underlayers in the mid- and shadow tones for the final colours. This effective build-up of few layers is reported in other paintings by Vermeer [29]. It is different from some of his contemporary high-end genre painters, especially Frans van Mieris (1635-1681) and Gerrit Dou (1613-1675), who used more complicated systems of paint layers [10,30]. The smooth paint surfaces in their very refined paintings were created using multiple thin applications of paint on top of each other. Cross-sections sometimes show as many as seven applications of paint [30].

\section{Contouring the face}

Vermeer's use of contours-defined as the borders between different parts of the composition, where one colour approaches another-is considered an important element in his paintings. Often he created soft transitions between the different forms by letting the adjacent paint areas slightly overlap. In other situations, he left a barely visible 'gap' between the forms [2, 29].

A prominent feature in the iron (Fe- $\mathrm{K})$ map is the contour-relatively rich in iron-around the lit side of her face, adjacent to the dark background (Fig. 2d). The contour is more clearly visible in the black and whiteinverted iron map, where it appears as a dark line between the two forms (Fig. 3b). By overlaying the high resolution MA-XRF maps (detail strip along the left side of the face, recorded at a step size of $100 \mu \mathrm{m}$ ) for the elements copper (Fig. 4b: $\mathrm{Cu}-\mathrm{K}$, as a marker for the background, see also Fig. 1i) and mercury (Fig. 4e: Hg-L, as a marker for the face), it is clear that the paint layers of the background and the pink flesh of the face do not touch each other (Fig. 4f). There is a distinct gap between them, which fits the iron zone of the map (Fig. 4c).

Comparison of the MA-XRF maps with a high-resolution 3D microscopic image (Fig. 4g) of the contour shows that the iron zone is in fact split into a brown underlayer and the cream-coloured underlayer of the face. The 3D digital micrograph revealed a brown paint layer within the $1 \mathrm{~mm}$-wide gap between the background and face (Fig. 4g: region 2). It corresponds with the iron zone in the MA-XRF map (Fig. 4c, g: region 2). It extends further than the contour-under part of the background and the face-but in the MA-XRF maps, the iron signal is blocked by the overlying paint layers. On the left, the brown colour is bordered by the dark background paint that contains copper (Fig. 4b, g: region 1). On the right, a small margin of the cream-coloured underlayer for the face (Fig. 4g: region 3) is visible; it was applied after the brown layer. This cream-coloured underlayer is not completely covered by the pink surface paint (Fig. 4g: region 4). MA$\mathrm{XRF}$ detected lead and iron in this small margin of the cream-coloured underlayer, but the iron signal is slightly lower than where the brown underlayer is exposed (but still higher than in the background and pink flesh paint) (Fig. 4c, d, g: region 3). The pink flesh paint contains vermilion and is visible in the mercury map (Fig. 4e, g: region 4).

The pigments associated with the contour and adjacent areas were identified with RIS, which lend confidence to the pigments inferred from MA-XRF. The RIS spectra are representative of the surface of the material, and the interpretation of where the RIS signal is originating from is more straightforward than with MA-XRF. Although the collected MA-XRF signal is sometimes dominated by surface layers if the XRF emission from underlying layers is absorbed, in some areas it may contain spectral contributions from the entire paint stratigraphy. To enhance 

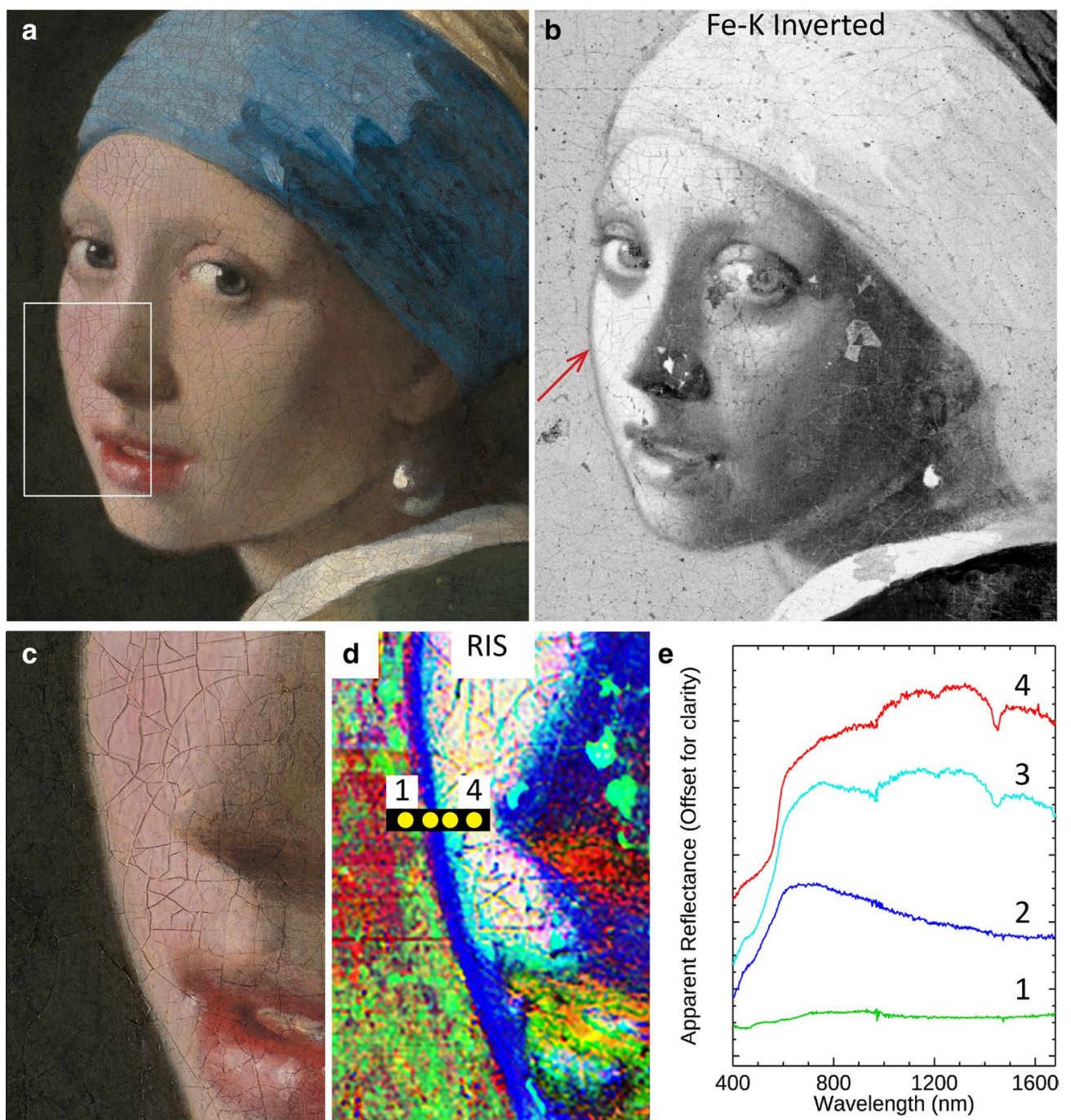

Fig. 3 MA-XRF (0.4 mm/pixel) and RIS ( $0.17 \mathrm{~mm} /$ pixel) maps showing a contour around the face of the Girl. a Visible light image. René Gerritsen Art \& Research Photography, $\mathbf{b}$ and corresponding black and white-inverted MA-XRF map of iron (performed in Photoshop). c Colour detail of the Girl's face, area marked in $\mathbf{a}$, and $\mathbf{d}$ corresponding false-colour first derivative RIS image showing the location of four regions with different reflectance spectra. e Reflectance spectra from the four regions identified in $\mathbf{d}$

the spectral differences between the pigments used in and around the contour, the first derivative of the RIS cube was examined. In the false-colour first derivative image (Fig. 3d), four distinct regions around and including the contour (identified in Fig. 4g) can be seen. To identify the pigments present in these regions, reflectance spectra from the RIS cube were examined and are shown in Fig. 3e. On the right is: a light pink area that contains vermilion (sharp inflection point near $580 \mathrm{~nm}$ ) with lead white (absorbance feature at $1449 \mathrm{~nm}$ ) (Fig. 3d, e: region 4). Next is an aqua-coloured region that contains iron ochre (inflection point near $565 \mathrm{~nm}$ ) with some vermilion and lead white (Fig. 3d, e: region 3). The blue region has some iron ochre (inflection point near $540 \mathrm{~nm}$ ) and is likely painted on an infrared-absorbing underlayer (Fig. 3d, e: region 2). The green/red region shows spectral features characteristic of the dark background (Fig. 3d, e: region 1) [13]. The mottled appearance of the background in the false-colour image is due to slight spectral inconsistencies, which are more pronounced in the first derivative spectra. These results are consistent with the four regions identified in the visible light image in Fig. $4 \mathrm{~g}$, where the surface layer of the face contains vermilion and lead white, but the vermilion-rich layer does not extend to the very edge of the left (her proper right) cheek. Instead, an ochre-rich paint (possibly containing 


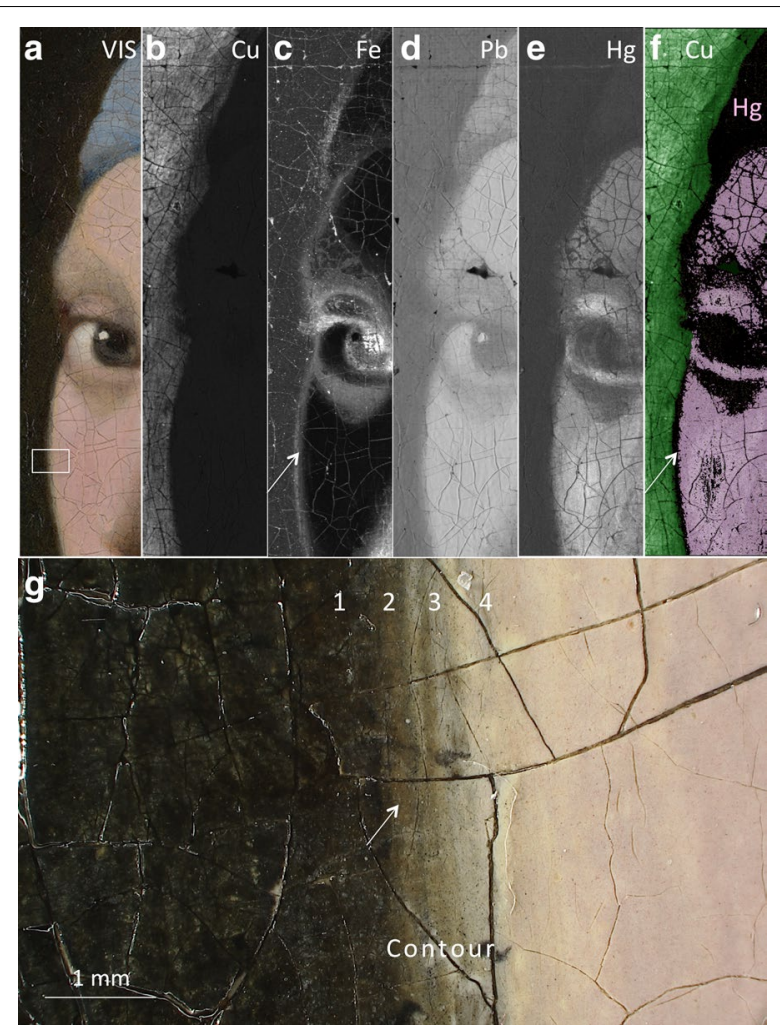

Fig. 4 High-resolution MA-XRF maps (0.1 mm/pixel) of a detail $(240 \times 24 \mathrm{~mm})$ of the face of the Girl. a Visible light image, and corresponding MA-XRF maps: $\mathbf{b}$ copper, $\mathbf{c}$ iron, $\mathbf{d}$ lead, e mercury, and $\mathbf{f}$ overlay of copper (green) and mercury (pink). There is a gap between the paint layers of the background (Cu-containing) and the paint layers of her face (Hg-containing) that is rich in iron. $\mathbf{g}$ The 3D digital micrograph shows the brown, iron-rich sketch paint (region 2) showing through at the contour around her face. The area shown in $\mathbf{g}$ is represented by a white box in $\mathbf{a}$

some vermilion) and lead white are present at the edge, which is likely the cream-coloured underlayer of the face (Fig. 4g: region 3). The next type of reflectance spectra contains ochre on top of a dark layer, as evidenced by the low reflectance in the near-infrared spectral region. This is likely the brown underlayer observed (Fig. 4g: region 2 ), which is painted on top of an infrared-absorbing layer, probably the grey ground, which contains carbon black [31]. The reflectance spectra from the background show spectral features in the visible spectral region associated with the glaze, and a similar low reflectance in the NIR associated with a dark underlayer.

Vermeer applied the brown underlayer at an early stage of the painting process, and left it partly visible to create a soft contour around the face. After applying the brown underlayer (Fig. 4g: region 2), he painted the underlayer of the Girl's skin (Fig. 4g: region 3), then the upper layer of the skin (Fig. 4g: region 4)-each time leaving part of the preceding layer visible. This gradual stepwise transition from background to face, leaving a barely visible 'gap', creates a soft contour between the two colour areas, and contributes to the overall spatial illusion of the composition. A similar technique has been observed for the contour of the neck of Vermeer's Study of a Young Woman (c. 1665-1667, The Metropolitan Museum of Art, New York), and for the right contour of Vermeer's Lady Seated at the Virginal (c. 1675, The National Gallery London) [2].

\section{Facial features}

Seamless transitions from one form to another was an effect Vermeer exploited when he painted the Girl's facial features. Girl with a Pearl Earring is considered to be a tronie rather than a portrait of a specific person; this may be why her facial features are idealised and somewhat indistinct, but look convincing from a distance [3]. The bridge of her nose has no contour, and its tip blends into her cheek. The Girl has been described as having alopecia, as she appears to have no eyebrows or eyelashes [32]; however, the 2018 Girl in the Spotlight research showed that the eyelashes of the right (her proper left) eye are visible as tiny black, hatched lines at high magnification (Fig. 2a). The eyelashes of the left (her proper right, next to the background) were revealed for the first time in the MA-XRF map for iron (Fe-K) (Fig. 4c). They were thinly painted on top of the background using an iron-containing paint, visible as a negative image in the $\mathrm{K}, \mathrm{Ca}$, and $\mathrm{Cu}$ maps (Fig. 1g-i).

The Girl's eye contact with the viewer is one of the aspects that makes the painting so engaging. Part of the right (her proper left) eye became damaged and has been retouched, so Vermeer's painting technique is better visualised in the left eye (Fig. 4a). Multispectral infrared reflectography (MS-IRR, 900-2500 nm) showed that Vermeer indicated the location of each eye with a black dot at an early stage of planning the painting, but shifted the position of the pupil at the painting stage [31]. Vermeer prepared the coloured part of the eye with a dark brown circle. The dark brown paint contains no infraredabsorbing black pigments, but is primarily made up of earth pigments. The pupil and darker ring around the iris are visible in the MA-XRF map for iron (Fig. 4c); however, in the middle of the circle, the iron signal is blocked by the upper layer(s) of paint. Examination with the 3D digital microscope showed that he scumbled a light-coloured paint on top of the dark brown paint to create the iris, leaving the pupil and darker ring around the iris in reserve. The paint used for the iris appears warm in colour; however, because it was applied thinly, the turbid medium effect (blue-hued scattering) makes her eyes appear blue-grey. The eye and eyelid were contoured with reddish-brown and brown underlayers. Around the eye, 
Vermeer applied pink paint on top of the underlayers: it contains both lead white and vermilion (Fig. 4d, e). He left the underlayer somewhat visible to create the caruncle: the red spot at the corner of the eye. Using leadcontaining paint, Vermeer applied the white of the eye (sclera) and smoothly blended it with the flesh paint. He also painted a white dot over the iris to make a highlight. Later, presumably when these layers were dry, Vermeer returned to the eye to add two dots of impasto: one pink dot over the caruncle, and two overlapping white dots to reinforce the highlight in the eye (Fig. 4a). The white highlight in the eye applied at two different stages is similar to 'double dots' that were observed in other parts of the painting.

The Girl's lips are slightly parted, and their contours are smoothly blended with the upper layer of flesh paint. This blending, and the fact that a red glaze extends slightly over her teeth, creates the illusion that she is beginning to speak. The Girl's lips were built up using a red-brown underlayer containing red lake. Areas where the redbrown underlayer was left exposed are visible in the MAXRF map for potassium (K-K) (Fig. 1g). On top of this, he applied a dark pink layer containing vermilion, and a little lead white, red lake and earth pigments [13]. This was blended with a lighter pink paint to create a highlight at the centre of her lower lip. The highlight at the corner of her mouth - two dabs of light paint revealed during the 1994 treatment [1] - and the small white dots on her lips might have been applied when the paint was dry. Similar to the final dots of impasto in her eye, Vermeer made her lips appear moist using subtle light accents in the form of small round dots of paint that catch the light.

The Girl's ear is in shadow, and is barely defined against her skin. The top of the ear is tucked beneath her headscarf. MS-IRR revealed that Vermeer shifted the ear upwards, and adjusted the line between her cheek and the headscarf during the painting process [31]. He also softened the definition of the contour of the back of her neck where it meets the background $[4,14]$.

Previous researchers noticed the subtle reflection from the white collar on the Girl's chin and jawline [2]. Vermeer also masterfully captured this reflection in the earring. The pearl itself is barely defined; it has no contours, and no hanger that attaches it to her ear. Vermeer painted it efficiently with a thin scumble of white paint and a thick impasto highlight on top of the shadow of the Girl's skin [13, 33].

\section{Micro-sample analysis of the materials of the flesh paints Paint samples from light and shadow parts}

Results from non-invasive macroscopic imaging and surface examination showed that Vermeer built up his flesh paint efficiently in few layers, with a limited palette. The main pigments inferred from MA-XRF were lead white, vermilion, earth pigments, and red lake. The study of paint cross-sections helped support observations about the layer stratigraphy, and further characterise the materials Vermeer used to paint the Girl's face.

Two new sample locations were carefully selected, based on the results of macroscopic imaging: a light pink flesh tone from her forehead, and a dark flesh tone from the shadow on her cheek. These were embedded as cross-sections to compare the stratigraphy and pigment composition in the light and shadow areas. In the crosssection from the light pink flesh tone, light microscopy and SEM-EDX found at least three thick layers of paint (Fig. 5, layers 2, 3, 4), with a total thickness of almost $100 \mu \mathrm{m}$, applied on top of the warm grey ground (Fig. 5, layer 1). The ground contains chalk, lead white, earth pigments and fine carbon black [31]. The two creamcoloured underlayers (Fig. 5, layers 2,3) are composed of lead white, yellow earth, and occasional particles of red lake, quartz (inferred from EDX detection of Si and O), chalk, and fine (carbon-based) black. No vermilion was detected in the underlayers. Between the ground (Fig. 5, layer 1) and the lowest underlayer (Fig. 5, layer 2), a thin layer appears to be present (layer not numbered), which contains slightly more chalk particles. The pink surface paint (Fig. 5, layer 4) consists of lead white, vermilion, and a few particles of red lake, and yellow earth. Also, a single particle of the blue pigment ultramarine (inferred from the presence of $\mathrm{Na}, \mathrm{Al}, \mathrm{Si}$, and $\mathrm{S}$ ) was detected.

The cross-section from the shadow area shows a thick layer of warm grey ground (Fig. 6, layer 1, up to $75 \mu \mathrm{m}$ thick), followed by three very thin applications of paint (Fig. 6, layers 2, 3, 4), which have a total thickness of only 20 to $25 \mu \mathrm{m}$ : significantly thinner than the paint layers in the sample from the light flesh paint. The first brown underlayer (Fig. 6, layer 2) was found to contain small particles of bone black (inferred from EDX detection of $\mathrm{Ca}$ and $\mathrm{P}$ ) and red lake. A thin fluorescent organic layer (in the order of $1 \mu \mathrm{m}$, layer not numbered) is visible at the interface between the ground and brown underlayer. Comparable thin interlayers were also observed in crosssections from other areas in this painting, but the precise composition could not be identified [31]. On top of the brown underlayer is another more reddish underlayer (Fig. 6, layer 3), showing a stronger pink fluorescence in UV than the brown layer. Apart from red lake, it contains occasional particles of bone black, yellow earth and vermilion. The final paint layer that Vermeer applied is lighter in colour, containing lead white, yellow earth, a little red lake, vermilion, and small particles of bone black.

The comparison of the samples from the light and shadow tones confirm some of the findings from the imaging techniques. Vermeer applied the paint on the lit 

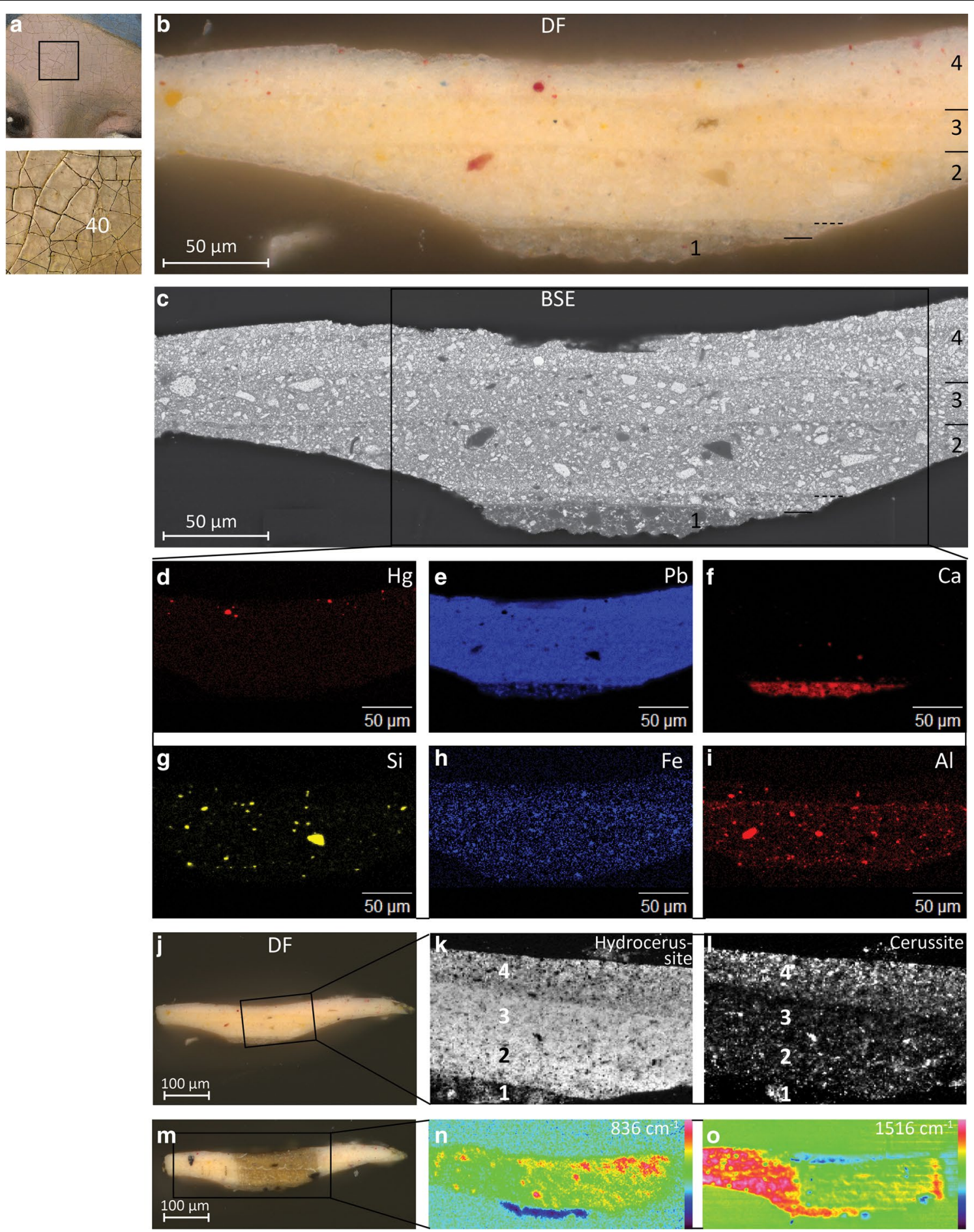

Fig. 5 Paint cross-section from a light pink flesh tone from her forehead (sample 40). a Sample location $\mathbf{b}$ light microscopic image, dark field. $\mathbf{c}$ Corresponding SEM backscattered-electron image, and EDX maps (area marked in $\mathbf{c}$ ) of: $\mathbf{d}$ mercury, e lead (Pb-M), $\mathbf{f}$ calcium, $\mathbf{g}$ silicon, $\mathbf{h}$ iron, $\mathbf{i}$ aluminium. $\mathbf{j}$ Light microscopic image showing location of $\mu$-XRPD analysis: $\mathbf{k}$ distribution map of hydrocerussite, I distribution map of cerussite. $\mathbf{m}$ Light microscopic image showing location of FTIR-ATR analysis: $\mathbf{n}$ distribution map of the $836 \mathrm{~cm}^{-1}$ band characteristic of cerussite (min. intensity $=-0.019$; max. intensity $=0.037$ ), o distribution map of the $1516 \mathrm{~cm}^{-1}$ band characteristic of lead carboxylates (min. intensity $=-0.047$; max. intensity $=0.138$ ). (Note the dark brown rectangle in the middle of the cross-section visible in $m$, which is the result of beam damage from $\mu$-XRPD analysis. FTIR-ATR analysis was done after $\mu$-XRPD analysis; it was not possible to remove the damage by polishing away the surface of the cross-section. The damaged area shows a very low carboxylate signal, meaning that the lead soaps and organics have decomposed.) 

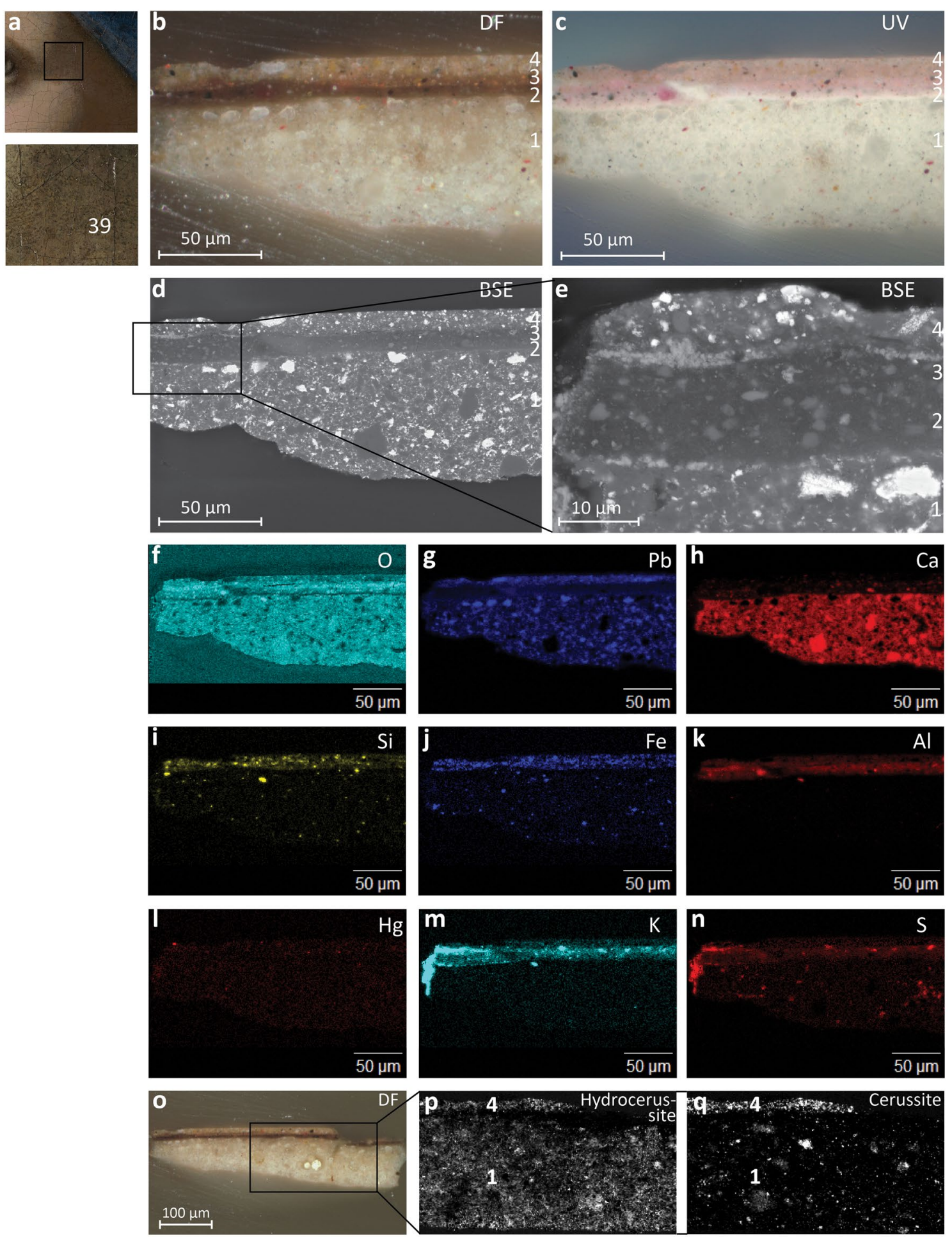

Fig. 6 Paint cross-section a dark flesh tone from the shadow on her cheek (sample 39). a Sample location, b light microscopic images, dark field, and $\mathbf{c}$ ultraviolet-induced fluorescence. $\mathbf{d}$ Corresponding SEM backscattered-electron image, e detail of $\mathbf{d}$, and EDX maps of $\mathbf{f}$ oxygen, $\mathbf{g}$ lead (Pb-M), $\mathbf{h}$ calcium, $\mathbf{i}$ silicon, $\mathbf{j}$ iron, $\mathbf{k}$ aluminium, I mercury, $\mathbf{m}$ potassium, $\mathbf{n}$ sulphur. $\mathbf{o}$ Light microscopic image showing location of $\mu$-XRPD analysis: $\mathbf{p}$ distribution map of hydrocerussite, $\mathbf{q}$ distribution map of cerussite 
side of the face rather thickly on top of several light-coloured underlayers, whereas he applied the shadow part more thinly (as a scumble) on top of dark paint layers so that the underlayers played a role in the final appearance. The pigments in the top layers are similar, but are in different proportions. The identification of pigments is in accordance with the results from RIS and macroscopic $\mathrm{X}$-ray powder diffraction imaging (MA-XRPD) published in companion articles $[13,34]$.

\section{Vermeer's use of different types of lead white}

The SEM backscattered-electron (BSE) images of the cross-sections taken from the light and shadow parts of the skin (Figs. $5 \mathrm{c}$ and $6 \mathrm{~d}$ ) show the lead white as the brightest white particles within the layers. In the sample from the light pink paint, Fig. 5c), the upper paint layer (Fig. 5, layer 4) appears denser and contains smaller particles than the underlayers (Fig. 5, layers 2 and 3). The lead white particles in the upper layer (Fig. 6, layer 4) of the shadow paint (Fig. 6d) are even finer, although there are also a few larger grains (clusters of particles) present.

Differences in particle size as observed with SEM can be correlated with differences in the proportions of hydrocerussite versus cerussite. XRPD can identify the crystalline phases of lead white, and quantify these relative proportions. The results of $\mu$-XRPD and MA-XRPD are described in depth in a paper by De Meyer et al. [15], and are summarised below. The MA-XRPD distribution maps (reflection mode) of hydrocerussite and cerussite show a much higher concentration of hydrocerussite in the lit side of the face than in the shadow side (images not shown). In contrast, cerussite is more uniformly distributed across the entire face (images not shown). The weight ratio of hydrocerussite to cerussite ( $\mathrm{HC}: \mathrm{C})$ is estimated 65:35 $( \pm 6)$ for the lit side of the face, while the shadow areas appear richer in cerussite showing a HC:C weight ratio of about 37:63 $( \pm 20)$. This suggests that Vermeer used different qualities of lead white in the flesh paints.

To further support these observations and to determine how hydrocerussite and cerussite are situated within the stratigraphy, the samples were analysed using synchrotron $\mu$-XRPD. Figure $5 k, 1$ show the distribution maps of hydrocerussite and cerussite in the sample from the light pink flesh. The surface paint layer (Fig. 5, layer 4) has a $\mathrm{HC}: \mathrm{C}$ weight ratio of about $65: 35( \pm 7)$, while a ratio of about 79:21 $( \pm 8)$ was calculated for the underlayers (Fig. 5, layers 2 and 3). The sample from the shadow paint confirms the use of a cerussite-rich lead white in the thin surface layer (Fig. 6, layer 4): it shows a HC:C weight ratio of about 48:52 ( \pm 5$)$ (Fig. 6p, q). The lead white in the ground of the same sample (layer 1) contains the highest amount of hydrocerussite, showing a $\mathrm{HC}$ :C weight ratio of about 83:17 $( \pm 8)$. This demonstrates that Vermeer employed different types of lead white in the build-up of his flesh paints.

FTIR-ATR examination of the sample from the lightcoloured flesh paint also showed a higher concentration of cerussite in the surface layer than in the underlayers, which is in accordance with the $\mu$-XRPD measurements. Cerussite is characterised by an absorption band at c. $836 \mathrm{~cm}^{-1}$ from out-of-plane bending vibration of carbonate (Fig. 5n) [35, 36].

This examination of Girl with a Pearl Earring using MA- and $\mu$-XRPD is the first time that different $\mathrm{HC}: \mathrm{C}$ ratios have been identified in Vermeer's lead white paints. SEM-EDX analysis of samples from The Art of Painting (1666-1668, Kunsthistorisches Museum, Vienna) detected extremely fine lead white particles in the upper paint layer of the white floor tiles, and coarser particles in the lower layers [37]. This shows that Vermeer was selective in the particle size; however, the $\mathrm{HC}: \mathrm{C}$ ratios were not analysed in samples from that painting.

In the left (lit) part of the face of Girl with a Pearl Earring, the SEM backscattered-electron images showed that Vermeer also used coarse lead white in the underlayers, and finer particles in the upper layer, although not as fine as in The Art of Painting. He probably chose the finer lead white to achieve a smooth surface finish. In the shadow part of her skin, he used an even finer lead white to apply a thin, light-coloured layer (scumble) over a dark underpaint. Presumably, he selected this for its specific optical and handling properties.

Previous studies have investigated the properties of different types of lead white, and their findings are somewhat contradictory [21-23]. Both the $\mathrm{HC}: \mathrm{C}$ ratio and the particle size seem to affect the optical properties. Polkownik observed that paintouts using a $100 \%$ cerussite paint were slightly less opaque than those using a $100 \%$ hydrocerussite paint; however she remarks that the opacity also depends on the particle size [23]. In their paint reconstructions, Albrecht and Stols-Witlox noted that the finest lead white obtained by levigation-separating light from heavy particles by leaving them to settle in a liquid and decanting them at different intervalswas very effective for creating a thin scumble over a dark underlayer [20]. In Girl with a Pearl Earring, we can assume that Vermeer chose the finer lead white because of its superior handling properties when used thinly as a scumble, while producing enough hiding power. Both post-processing methods-levigation, and washing and grinding in vinegar-can result in finer particles and more cerussite. 


\section{Lead isotope analysis}

Specific layers within cross-sections from Girl with a Pearl Earring were sampled for lead isotope analysis using a custom-designed microsample tool, which extracted microscopic samples containing lead white (5 to $20 \mu \mathrm{g}$ ) [38]. In total, eight different lead white-containing paints were analysed, originating from the ground, upper layers and underlayer(s) in the light and dark parts of the Girl's skin. The lead isotope ratios of these samples are presented in Table 1 and Fig. 7a, which shows ${ }^{206} \mathrm{~Pb} /{ }^{204} \mathrm{~Pb}$ plotted against ${ }^{207} \mathrm{~Pb} /{ }^{204} \mathrm{~Pb}$. Although there are minor variations in lead isotope ratios between the different samples and layers, these do not correlate with the function of the layer or the specific colour area. The lead isotope ratios for the light and shadow parts of the skin fall within analytical error for all isotope ratios. The samples from the ground show slightly more variation in lead isotope ratios than the ones from the paint layers. Evidence from computerised weave analysis suggests that Vermeer might have purchased a pre-primed canvas, so perhaps did not apply the ground himself [31]. There are several plausible explanations for the small heterogeneity of the lead isotopes of the ground. First, the lead white is present in a mixture with other pigments. Moreover, the lead ore itself is not fully homogeneous due to the fact that the geological processes that form lead ore deposits operate on a scale of $>10 \mathrm{~km}$ and result in ore fluids interacting with different types of rocks beneath where the ore is ultimately formed. Additionally, lead white production could potentially include a minor component of recycled lead. It is also possible that minor amounts of $\mathrm{Pb}$ containing dust and other contaminants $(<0.01 \%)$ were introduced during pigment production, paint making or paint application. All these processes potentially lead to detectable isotopic variations, which does not obscure the ultimate source of the $\mathrm{Pb}$.

Lead isotope ratios can be used to determine the geological source of the lead used to produce lead white. The isotopic results of galena ores (PbS) from some European mines in Italy, Greece, Spain and the United Kingdom are plotted in Fig. 7b. European ores sometimes overlap with each other; however, there are defined areas of the graph that show trends in ratios of lead isotopes. When the samples from Girl with a Pearl Earring are plotted on this graph, they are clearly within the United Kingdom (UK) region. In comparison to regional variations in lead isotope ratios recorded by lead ores Europe-wide, the observed isotopic heterogeneity of samples from the Girl is insignificant. Based on the production history of lead in the UK [39] and the newly determined lead isotope data, the most likely source of the lead used in Girl with a Pearl Earring is the highly productive region of Peak District of Derbyshire.
Given the differences in cerussite and hydrocerussite ratios and particle sizes identified using $\mu$-XRPD and SEM-EDX, one might expect that Vermeer used several distinct types of lead white. The evidence from lead isotope analysis shows that the lead white probably came from a single source, since there is, geologically speaking, insignificant variation in their isotope ratios. This single type of lead white was further processed to create pigments with specific properties: different varieties of lead white that varied in particle size and handling properties. The question remains open, however, whether the lead white was reprocessed within Vermeer's workshop, or whether these different varieties were available from the shop(s) where he purchased his pigments [40].

\section{Formation of new lead species}

Analyses of cross-sections also identified the formation of new lead species, formed over time as a result of chemical reactions between the lead white pigment, the oil medium, and other components in the paint. The SEM backscattered-electron images of the sample from the shadow paint (Fig. 6d, e) show light-grey amorphous zones in the underlayers (Fig. 6, layers 2 and 3). These are different from the distinct, strongly scattering particles of lead white, and indicate the formation of reaction products. They contain lead, potassium and sulphur (Fig. $6 \mathrm{~g}$, $m, n)$. FIB-STEM allowed parts of the sample to be analysed at greater spatial resolution (Fig. 8). The STEM image of a lamella from the underlayers also shows many small, dispersed particles distributed within the layers, in addition to the deposits at the top and bottom. Their elemental compositions could be determined more precisely without influence from the surrounding bulk of the sample. The STEM-EDX maps also show the presence of lead, potassium and sulphur in the small, dispersed lightgrey particles. The atomic ratios (S 38.55 At\%, K 34.05 At\%, $\mathrm{Pb} 18.65$ At\%) match the expected values of palmierite $\left(\mathrm{K}_{2} \mathrm{~Pb}\left(\mathrm{SO}_{4}\right)_{2}\right)$. Palmierite is a degradation product often found in Old Master paintings [41, 42], and in this painting it was also detected using MA- and $\mu$-XRPD [34]. Here it is likely to be associated with the red lake that is present predominantly in the red-brown underlayers of the shadow areas of the skin. The lake substrate is a source of potassium and sulphur. Lead comes from both the lead white-containing ground and surface layer. The STEM images show deposits of lead, potassium, and sulphur-probably in the form of palmierite-at the interfaces between ground and underlayers, and between underlayers and surface layers.

FTIR-ATR is an effective technique for the characterisation and localisation of lead soaps. The asymmetric stretch vibration of the lead carboxylate group $v_{\mathrm{as}}\left(\mathrm{COO}^{-}\right)$generates an intense absorption band in the 


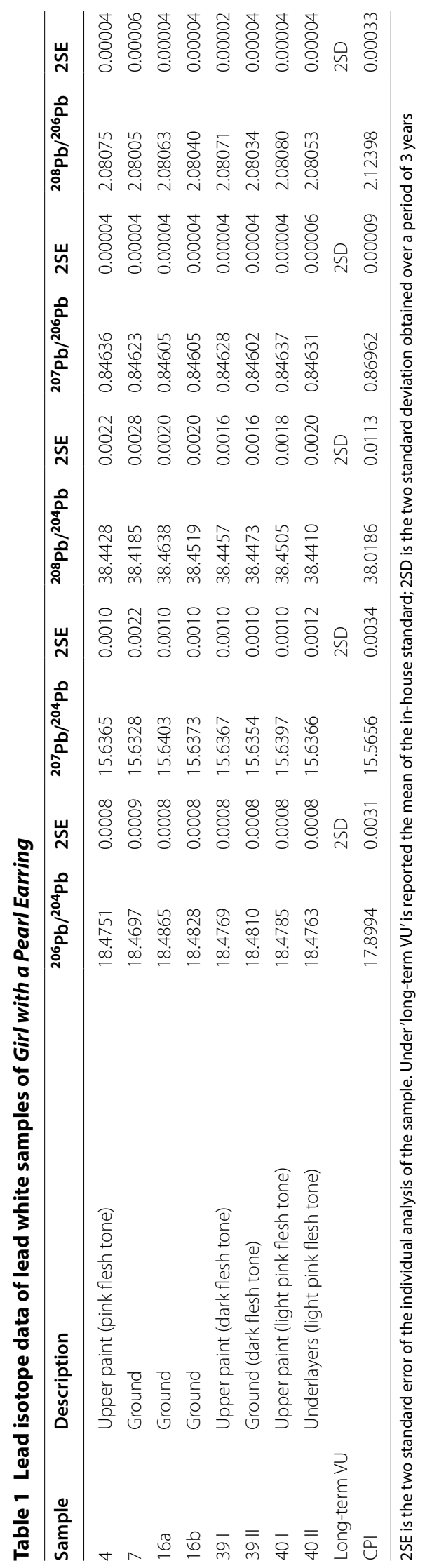




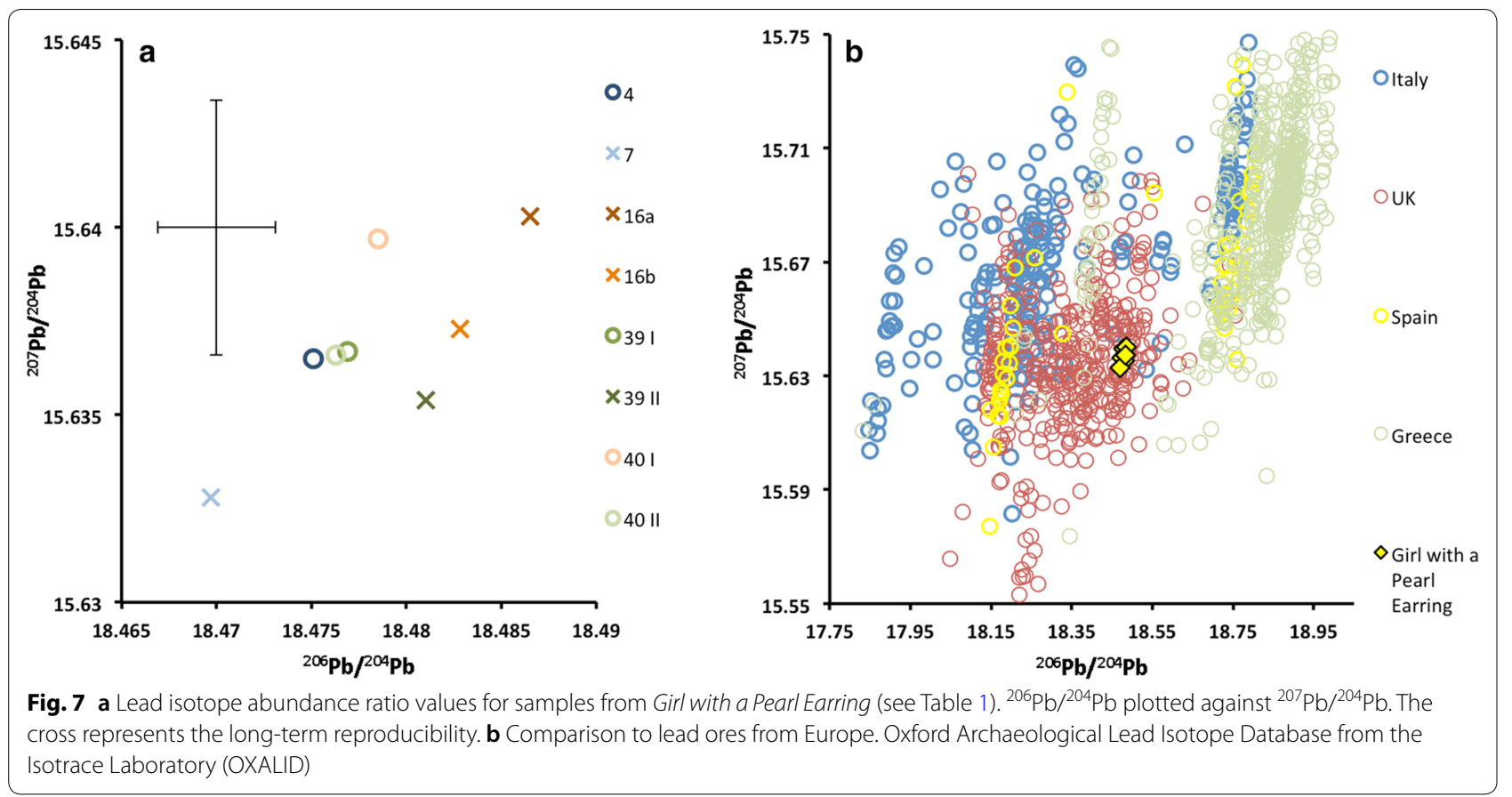

1550-1500 $\mathrm{cm}^{-1}$ wavenumber region [36]. Figure 5o shows the distribution of the $1516 \mathrm{~cm}^{-1}$ band, characteristic of lead carboxylates, in the cross-section of the light pink flesh. Lead soaps are present in both the lead white-containing under- and surface layers. FTIR-ATR of the sample of the shadow area also identified lead carboxylates in the thin surface layer (data not shown). The greyish amorphous rims around some of the lead white particles, visible in the SEM backscattered-electron images, suggest that these have partly converted into soaps [43].

Lead soaps form as a consequence of reactions of lead white pigment with reactive carboxylic acid groups from the oil binder. Loss of pigment as a result of lead soap formation can cause increased transparency and consequent darkening, since the light penetrates deeper into the paint [44-46]. In Girl with a Pearl Earring, this effect is most obvious in the shadow parts, because the red-brown underlayers become more visible. In the light pink flesh tones, the thicker layers - and the fact that the underlayers are lighter in colour than the upper layermakes this effect less noticeable. Over time, this must have made the contrast between the lit and shadow parts of the face starker.

Although we can still appreciate the smooth paint handling and seamless transitions in the face as it appears to us today (Figs. 1a and 2a), chemical reactions and physical changes (including abrasion) have compromised the
Girl's condition and appearance since Vermeer painted her.

\section{Conclusions}

The combination of non-invasive macroscale imaging with microscopic examination of the paint surface, and (re-)analysis of cross-sections, proved to be essential for understanding how Vermeer achieved the soft modelling of skin tones. MA-XRF identified the elements, from which the main pigments used in the skin tones were inferred, and provided some clues about the painting process and how Vermeer built up the light, midand shadow tones. This was supported by microscopic examination of the paint surface and cross-sections, which revealed the complete stratigraphy_from ground to surface paint-in selected spots. Analysis of two new samples, collected from a light pink and a shadow tone, further characterised the materials Vermeer used in the different layers. This approach corroborated visual observations made in the 1990s, and made some novel discoveries.

The combination of MA-XRF, RIS and high-resolution 3D digital microscopy helped understand how Vermeer created the soft contour around the Girl's face by leaving underlayers partly exposed. The upper layers of the background and face do not touch each other.

Vermeer built up the light areas of the face with a creamy white underlayer and a pink paint on top. Conversely, the mid-and shadow tones were underpainted 
with a darker colour: grey or brown for the mid-tones and a darker, reddish brown for the shadow tones. He finished the darker tones with thin applications of a lighter colour (scumble), allowing the underpaint to remain somewhat visible and creating a cooler final appearance (blue-hued scattering). The underlayers show a stronger light-dark contrast than is visible in the final image. Also, the paint in the light areas were applied much more thickly than in the shadow. The cross-sections showed a thickness of almost $100 \mu \mathrm{m}$ for the build-up of the light paint, as compared to 20-25 $\mu \mathrm{m}$ for the shadow paint: almost four times thicker.

The upper paint layers of the face were applied once the underlayers were dry. They were smoothly blended, presumably with a dry brush, to create an almost seamless transition from light to dark. The Girl's facial features are also somewhat indistinct. The eyelashes of the right (her proper left) eye only became visible at high magnification, while the XRF map of iron revealed for the first time the eyelashes of the left (her proper right) eye. The latter also helped to establish how Vermeer built up the eye itself. He applied the final highlights on her eyes and mouth in the form of 'double dots' of impasto paint.

Synchrotron radiation $\mu$-XRPD, SEM-EDX, and FTIR-ATR revealed that Vermeer used a lead white with finer particles and higher cerussite content in the surface paint layers. The finest quality was found in the thin, light-coloured layer (scumble) that was applied over the reddish-brown underpaint in the shadow tone. This shows that Vermeer was highly selective in the particle size of his lead white. Lead isotope analysis of eight different lead white-containing paints in Girl with a Pearl Earring showed very little variation in the isotope ratios. It identified the region of Peak District of Derbyshire in UK as most likely source of the lead used to produce the different qualities of lead white found in Girl with a Pearl Earring. SEM-EDX, FIB-STEM, and FTIR-ATR also identified lead-containing reaction products in the flesh paints: lead soaps and a compound rich in lead, potassium and sulphur-probably palmierite $\left(\mathrm{K}_{2} \mathrm{~Pb}\left(\mathrm{SO}_{4}\right)_{2}\right)$, here associated with the substrate of red lake pigment.

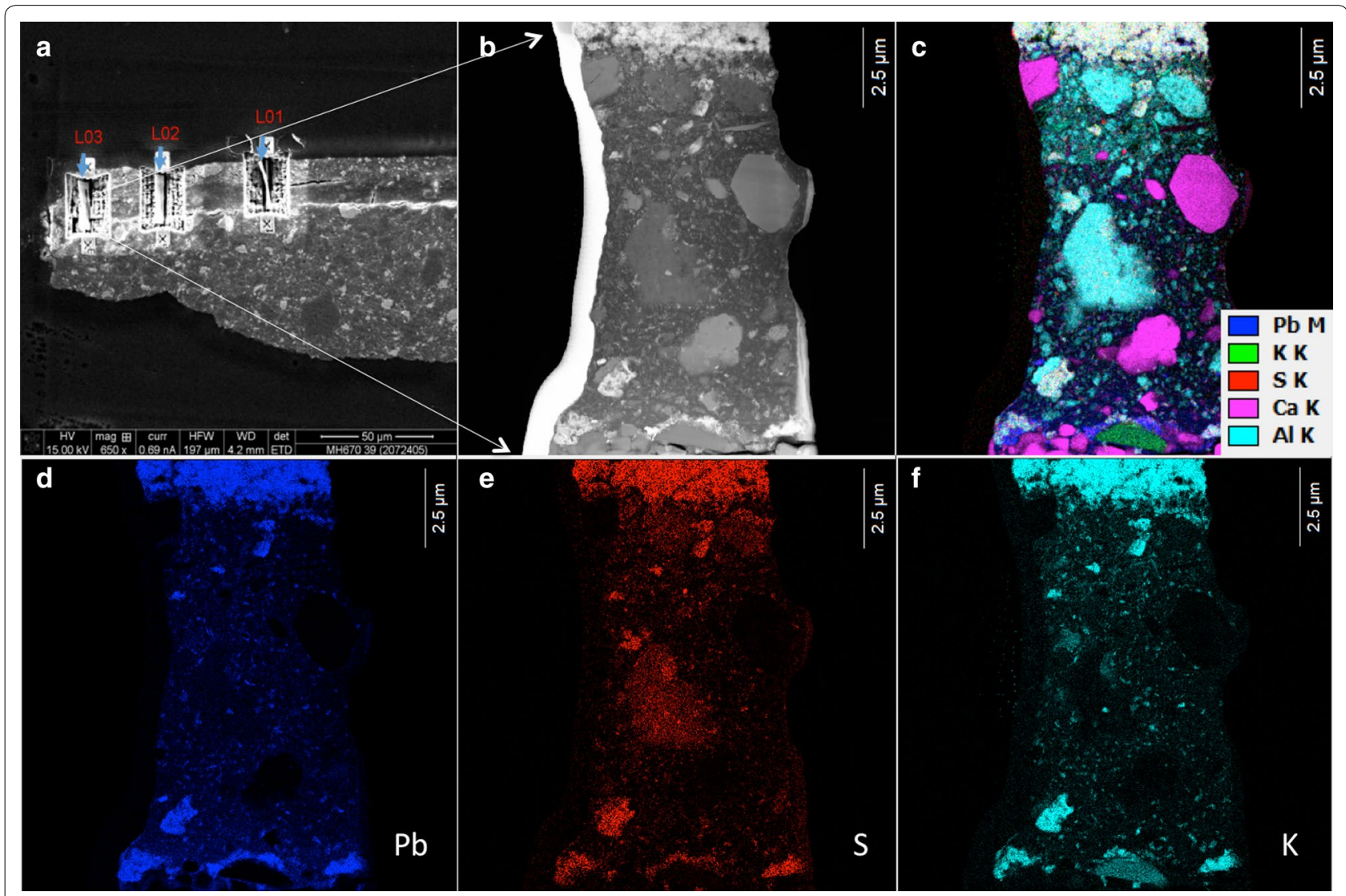

Fig. 8 FIB-STEM analysis of the sample from the shadow part of the skin (see Fig. 8). a SEM backscattered-electron image showing FIB lamella locations. b STEM image of FIB lamella L03 from underlayers. c STEM-EDX overlay of b: lead (Pb-M) (blue), potassium (green), sulphur (red), calcium (pink), aluminium (cyan). STEM-EDX maps of: $\mathbf{d}$ lead (Pb-M), e sulphur, $\mathbf{f}$ potassium 
In conclusion, Vermeer worked in a very structured and effective manner to paint the smooth flesh tones of Girl with a Pearl Earring. It has been noted by previous researchers that, although Vermeer used a variety of techniques to render flesh tones and subtle light effects, he would never repeat himself; instead, he "continued to see things afresh" [7].

\section{Experimental methods}

\section{Non-invasive chemical imaging}

\section{Macroscopic X-ray fluorescence (MA-XRF) scanning}

MA-XRF maps of the entire painting were collected in two scan sessions (total times $25 \mathrm{~h}$ ) using the Bruker M6 Jetstream. [47] After this, a $240 \times 24 \mathrm{~mm}$ strip along the left side of the Girl's face was selected to scan at smaller step size and with longer dwell times (total times $19 \mathrm{~h}$ ). The instrument consists of a measuring head equipped with a $30 \mathrm{~W}$ rhodium-target microfocus X-ray tube, a polycapillary lens, and a $60 \mathrm{~mm}^{2}$ XFlash silicon drift detector (SDD) with a beryllium window (energy resolution $<145 \mathrm{eV}$ at $\mathrm{Mn}-\mathrm{K}_{\alpha}$ ). By slowly moving the measuring head on the $X Y$-motorised stage, the painting was scanned pixel by pixel, line by line. By recording the emitted X-ray fluorescence radiation, the chemical elements present in the paint (associated with specific pigments) can be identified. With the Bruker M6 Jetstream, only elements heavier than silicon can be detected. The entire painting was scanned at $50 \mathrm{kV}$ and a current of $600 \mu \mathrm{A}$, with a $400 \mu \mathrm{m}$ step size, and a dwell time of $125 \mathrm{~ms}$. The distance between the scanning head and the paint surface was set at approximately $10 \mathrm{~mm}$, corresponding to an X-ray spot size of c. $250 \mu \mathrm{m}$. For the detail scan of the face, a $100 \mu \mathrm{m}$ step size and a dwell time of $200 \mathrm{~ms}$ were used; the working distance was 6-7 $\mathrm{mm}$, corresponding to an X-ray spot size of c. $100 \mu \mathrm{m}$. All data were collected with the Bruker M6 Jetstream software package. The acquired data cubes were then exported as raw files and processed and stitched using PyMca and Datamuncher software to produce elemental distribution maps [48].

\section{Reflectance imaging spectroscopy: visible-to-near-infrared (VNIR: 400-1000 nm) and shortwave infrared (SWIR: 967-1680 $\mathrm{nm}$ )}

Hyperspectral reflectance image cubes of the entire painting were collected with optimised whiskbroom linescanning imaging spectrometers (Surface Optics Corporation, USA) that have been previously described [49]. The VNIR imaging spectrometer (V10E Specim Corp., Finland) was coupled to a backside illuminated Si CCD array (ProEM1024, Princeton Instruments, USA) operating from 400 to $1000 \mathrm{~nm}$ with $2.5 \mathrm{~nm}$ sampling, at a light level of 1200-1500 lx and integration time of $150 \mathrm{~ms}$ per line. The SWIR imaging spectrometer was coupled to an InGaAs array (SUI 640HSX-1.7RT, Sensors Unlimited, USA) operating from 967 to $1680 \mathrm{~nm}$ with $3.4 \mathrm{~nm}$ sampling, $700 \mathrm{~lx}$, and an integration time of $33 \mathrm{~ms}$ per line. The image cubes were dark-corrected, flat-fielded, and calibrated to apparent reflectance using diffuse reflectance standards (Labsphere Inc, USA). The calibrated image cubes were spatially registered using a point-based algorithm [50], and the resulting spatial sampling at the painting was $0.17 \mathrm{~mm} /$ pixel for both cameras.

\section{Surface examination and digital microscopy \\ Stereomicroscopy}

The painting was examined at up to $40 \times$ magnification using a Zeiss Universal S2 stereomicroscope to characterise the painting sequence.

\section{High-resolution 3D digital microscopy}

The painting was examined using the Hirox RH-2000 3D digital microscope on a motorised 'bridge' stand with a $500 \times 500 \mathrm{~mm}$ automatic motorised $X Y$ stage $(200 \mathrm{~nm}$ steps). The 'bridge' stand was made specifically for the Girl in the Spotlight project to accommodate the painting, which was placed horizontally. The microscope zoom lens MXB-5000REZ was mounted on the Hirox FB-E $Z$-axis block with $30 \mathrm{~mm}$ motorised movement $(50 \mathrm{~nm}$ steps). It can achieve spatial sampling from $4.4 \mu \mathrm{m} /$ pixel $(35 \times)$ down to $0.03 \mu \mathrm{m} /$ pixel $(5000 \times)$; for the images in this paper, the former was used. The illumination used was mixed: raking light (100\% light intensity) and ring light/dark field (10\% light intensity). At $35 \times$ magnification $(4.4 \mu \mathrm{m} /$ pixel $)$, the tile size is $8.5 \times 5.28 \mathrm{~mm}$.

The complete painting was automatically scanned at a sampling resolution of $4.4 \mu \mathrm{m} /$ pixel with a $30 \%$ overlap: the microscope acquired a series of images in the $Z$-axis, capturing each focus layer and then combining them in one single all-in-focus image (also known as $Z$-stacked or extended depth of field). The microscope then moved in the $X$ and/or $Y$ direction to the next tile, and the process automatically started again, so that a total of 9100 $Z$-stacked images were acquired in approximately $14 \mathrm{~h}$. For each tile, a $Z$-stacked image as well as a TDR file (Hirox 3D file format) were created, which included true colours and altitude, so that the $X Y Z$ coordinates are registered for each pixel.

The Hirox RH-2000 main unit software (which was modified specifically for this project) was used to calibrate and display a live image, then to create full auto $Z$-stacked 3D data and to program a fully automatic $X Y Z$ acquisition with selectable overlap (offline tiling without any pixel size limit in the full scan). Stitching the $4.4 \mu \mathrm{m} /$ pixel resolution images created an all-in-focus stitched 
image of the full painting at approximately 10 billion pixel resolution.

\section{Micro-sample analysis \\ Paint micro-samples and sample preparation}

In 2018, new microscopic paint samples were collected from a light, pink flesh tone (forehead, sample 40) and a shadow tone (cheek, sample 39) from the Girl's face in order to analyse and compare their stratigraphies and materials. The paint samples were embedded in Technovit 2000 LC mounting resin-a one-component methacrylate that cures under visible blue light (Heraeus Kulzer GmbH, Germany) - and polished using a sample holder and Micromesh sheets up to grade 12,000 (MicroSurface Finishing Products Inc., Wilton, Iowa, USA) [51]. The samples were examined using: light microscopy, SEM-EDX, FIB-STEM, $\mu$-XRPD, FTIR-ATR, and lead isotope analysis. Samples of lead white-containing paints collected in the 1990s were also selected for lead isotope analysis. These included sample 4 (pink flesh, original location unknown); grounds of samples 7 and $16 \mathrm{a}$ and $\mathrm{b}$ (dark brown paints, original locations unknown).

\section{Light microscopy (LM)}

A Zeiss Axio Imager.A2m microscope equipped with a Zeiss AxioCam MRc5 digital camera was used to examine the polished cross-sections 39 and 40, and to capture images at spatial resolutions of $0.27 \mu \mathrm{m} /$ pixel $(200 \times)$ and $0.11 \mu \mathrm{m} /$ pixel $(500 \times)$ in bright field, dark field and ultraviolet (UV-A). Luminescence images were obtained with a LED $365 \mathrm{~nm}$ light source, and a filter cube composed of a $365 \mathrm{~nm}$ excitation filter (EX G 365), a beamsplitter at $395 \mathrm{~nm}$ (BS FT 395), and an emission long-pass filter at 420 nm (EM LP 420)).

\section{Scanning electron microscopy-energy dispersive X-ray analysis (SEM-EDX)}

SEM backscattered-electron images of the uncoated cross-section samples 39 and 40 were acquired with a FEI NovaNano SEM 450 variable pressure electron microscope operated at low vacuum (70 Pa), and an accelerating voltage of $20 \mathrm{kV}$. The SEM was equipped with a ThermoFisher NSS EDX system to yield elemental composition of the pigments within the layers.

EDX mapping was done using a JEOL 7000F high-vacuum SEM coupled to a ThermoFisher NSS EDX system with dual $30 \mathrm{~mm}^{2}$ silicon drift detectors. The samples were carbon-coated (Leica ACE600 nominally $15 \mathrm{~nm}$ thick) prior to EDX mapping to improve surface conductivity. All the samples were mapped using spectral imaging at either $500 \times$ or $1000 \times$ magnification. Each map consists of $256 \times 202$ pixels and the collection time was typically $30 \mathrm{~min}$. The step size of the images was $1.04 \mu \mathrm{m} /$ pixel and $0.52 \mu \mathrm{m} /$ pixel for the $500 \times$ and $1000 \times$ images, respectively.

\section{Focused ion beam-scanning transmission electron microscopy (FIB-STEM)}

The combination of STEM and EDX was used to 'map' the element distribution in thin sections prepared from cross-sections 39 and 40 using the FIB. The thin sections were prepared using the standard ex situ lift-out method [52]. This involves cutting out a cross-section specimen from its substrate and transferring this onto a thin support membrane using a micromanipulator. In the case of paint cross-sections this means that the section can be milled directly from the bulk sample. All thin sections were prepared using a FEI Helios dual beam system. The rough milling was done using a beam current of $21 \mathrm{nA}$ and for the final polishing it was $93 \mathrm{pA}$. The tilt off-set was $0.6^{\circ}$. The nominal thickness of the sections was $200 \mathrm{~nm}$ with a width of $20 \mu \mathrm{m}$ and height of $8 \mu \mathrm{m}$.

Spectral images were made at resolutions ranging from $26 \mathrm{~nm} /$ pixel $(20,000 \times)$ up to $2.2 \mathrm{~nm} /$ pixel $(240,000 \mathrm{x})$ with an accelerating voltage of $200 \mathrm{keV}$. Each map consists of $512 \times 512$ pixels and the collection time was typically between 5 and $15 \mathrm{~min}$. The spatial resolution of the images was $26 \mathrm{~nm} /$ pixel and $2.2 \mathrm{~nm} /$ pixel for the $20,000 \times$ and $240,000 \times$ images, respectively. The microscope used for this work was a JEOL2800 with two Centuro EDX silicon drift detectors. The measurements were made at the Shell Technology Centre Amsterdam (STCA).

\section{Fourier transform infrared-attenuated total reflectance spectroscopy (FTIR-ATR)}

FTIR spectral data of cross-sections 39 and 40 were collected on a Perkin Elmer Spectrum 100 FTIR spectrometer combined with a Spectrum Spotlight 400 FTIR microscope equipped with a $16 \times 1$ pixel linear mercury cadmium telluride (MCT) array detector. A Perkin Elmer ATR imaging accessory consisting of a germanium crystal was used for ATR imaging. The spectral resolution was $16 \mathrm{~cm}^{-1}$. The mapping area was $300 \times 400 \mu \mathrm{m}$ in size, with a spatial resolution of $6.25 \mu \mathrm{m} /$ pixel.

\section{Synchrotron: Micro X-ray powder diffraction ( $\mu$-XRPD)}

Cross-sections 39 and 40 were analysed using $\mu$-XRPD. The samples were analysed at beamline P06 (PETRA-III, DESY, DE), a hard X-ray micro- and nano-probe beamline suited for X-ray powder diffraction imaging experiments at the (sub-) microscopic scale. A Kirkpatrick-Baez optical system focuses the beam to a diameter of $0.5 \mu \mathrm{m}$ and a flux of approximately $10^{10}$ photons $\mathrm{s}^{-1}$ with a primary energy of $21 \mathrm{keV}$. The samples were placed in a sample holder, at a distance of $18 \mathrm{~cm}$ in front of the detector, capable of moving in the $X Y Z$ direction over a distance of 
several millimetres. An EIGER X $4 \mathrm{M}$ detector (Dectris Ltd., DE) was used to collect the diffraction signals.

\section{Lead isotope analysis}

Small quantities of material were extracted from embedded cross-sections using a micro-scalpel: a purpose-designed tool developed for the purpose of micro-invasive sampling of cross-sections [38]. The micro-scalpel uses a blade that allows the operator to sample specific layers of a cross-section with a minimum thickness of $10 \mu \mathrm{m}$. Layers containing particles of lead white were chosen for lead $(\mathrm{Pb})$ isotope analysis to study the provenance of the $\mathrm{Pb}$. Five cross-sections were subsampled (samples 4, 7, 16, 39, 40) and 8 different samples analysed (Table 1). After sampling, the cross-sections were re-polished to allow reuse for further analysis or to be retained as reference material. Between 5 and $20 \mu \mathrm{g}$ of pigment was obtained per sample.

The lead component in the samples was isolated using a process of dissolution and extraction via liquid chromatography. $50 \mu \mathrm{L}$ of the lead solution was taken and mixed in $10 \mathrm{ml} 5 \% \mathrm{HNO}_{3}$ to perform ICP-MS analysis to assess the amount of $\mathrm{Pb}$ in the samples. An aliquot was taken from each sample and diluted in order to obtain $2 \mathrm{~mL} 1 \%$ $\mathrm{HNO}_{3}$ at $50 \mathrm{ppb} \mathrm{Pb}$ solution for analysis by MC-ICP-MS (Thermo Scientific Neptune).

Instrumental mass bias was corrected using standard sample bracketing, using NBS 981 as bracketing standard. The samples were introduced using a CETAC Aridus II $^{\mathrm{TM}}$ Desolvating Nebulizer System, using approximately 4. $\mathrm{L} \mathrm{min}{ }^{-1}$ argon sweep gas and $20 \mathrm{~mL} \mathrm{~min}^{-1}$ nitrogen $\left(160{ }^{\circ} \mathrm{C}\right)$. Mass ${ }^{202} \mathrm{Hg}$ was recorded to correct for isobaric interferences of ${ }^{204} \mathrm{Hg}$ on ${ }^{204} \mathrm{~Pb}$.

The total procedure bank was measured by isotope dilution, using a ${ }^{208} \mathrm{~Pb}$ spike, yielding $50 \mathrm{pg} \mathrm{Pb}$. The $50 \mathrm{ppb} \mathrm{Pb}$ solutions typically yielded a signal of around $20 \mathrm{~V}$, using a $10^{11} \Omega$ resistor. The in-house standard CPI $\mathrm{Pb}$ as well as NBS 981 were analysed in between sample analyses to assess the accuracy of the analyses. The $\mathrm{Pb}$ isotope ratios of both standards were within analytical uncertainties indistinguishable from long-term mean values.

\footnotetext{
Abbreviations

FIB-STEM: focused ion beam-scanning transmission electron microscopy; FTIR-ATR: Fourier transform infrared spectroscopy-attenuated total reflectance spectroscopy; HPLC: high performance liquid chromatography; MA-XRF: macroscopic X-ray fluorescence imaging; MA-XRPD: macroscopic X-ray powder diffraction imaging; RIS: refectance imaging spectroscopy; SEM-EDX: scanning electron microscopy-energy dispersive X-ray analysis; UHPLC-PDAFLR: ultra-high-performance liquid chromatography with a photodiode array, attached to a fluorescence detector.
}

\section{Acknowledgements}

The research project The Girl in the Spotlight is a Mauritshuis initiative, led by paintings conservator Abbie Vandivere, with a team of internationally recognised specialists working within the collaborative framework of the Netherlands Institute for Conservation + Art + Science + (NICAS). The authors would also like to thank the following people for their useful discussions, and assistance with analysis and technical examination: René Gerritsen and Jaap Hoogerdijk (René Gerritsen Art \& Research Photography); Bob van Wingerden (Shell Technology Centre Amsterdam); Klaas Jan van den Berg and Art Ness Proaño Gaibor (Cultural Heritage Agency of the Netherlands); Geert van der Snickt (University of Antwerp); Joris Dik (Delft University of Technology); Marya Albrecht (Mauritshuis); Maartje Stols-Witlox (University of Amsterdam); Jan Garrevoet, Matthias Alfeld and Gerald Falkenberg (beamline P06 at the PETRAIII (DESY) synchrotron facilities).

\section{Authors' contributions}

AvL: collection of MA-XRF data, MA-XRF data processing, light microscopic and SEM-EDX paint analysis, evaluation of painting sequence and brushwork style, data interpretation related to Vermeer's technique; AV: coordinator of the Girl in the Spotlight project, evaluation of painting sequence and brushwork style, data interpretation related to Vermeer's technique; JKD, KD: collection of RIS data, RIS data processing and interpretation. SDM, FV, VG, KJ: collection of $\mu$-XRPD data, $\mu$-XRPD data processing. EL: collection of 3D digital microscopy. RH: SEM-EDX mapping and FIB-STEM. SdG: collection of FTIR-ATR data. PDI, GD: lead isotope analysis and data interpretation. AvL and AV drafted the manuscript. JKD, KD, SDM, FV, VG, PDI, GD gave valuable input and comments. All authors read and approved the final manuscript.

\section{Funding}

The Netherlands Institute for Conservation + Art + Science + funded the participation of the NICAS partners in the project, including use of analytical equipment and the time devoted to the project by scientists from the RCE, TU Delft, University of Amsterdam and the Rijksmuseum. The Girl in the Spotlight project was made possible with support from the Johan Maurits Compagnie Foundation

\section{Availability of data and materials}

The datasets used and/or analysed during the current study are available from the corresponding author on reasonable request. The datasets supporting the conclusions of this article are included within the article.

\section{Competing interests}

The authors declare that they have no competing interests.

\section{Author details}

${ }^{1}$ Conservation Department, Mauritshuis, Plein 29, 2511 CS The Hague, The Netherlands. ${ }^{2}$ Conservation \& Science, Rijksmuseum, Hobbemastraat 22, 1071 ZC Amsterdam, The Netherlands. ${ }^{3}$ Scientific Research Department, National Gallery of Art, 6th and Constitution Avenue NW, Washington, DC 20565, USA. ${ }^{4}$ AXES, Department of Chemistry, University of Antwerp, Groenenborgerlaan 171, 2020 Antwerp, Belgium. ${ }^{5}$ Hirox Europe - Jyfel Corporation, 300 Route Nationale 6, Le bois des côtes, 69760 Limonest, France. ${ }^{6}$ Shell Global Solutions International B.V., Grasweg 31, 1031 HW Amsterdam, The Netherlands. ${ }^{7}$ Cultural Heritage Agency of the Netherlands (RCE), Hobbemastraat 22, 1071 ZC Amsterdam, The Netherlands. ${ }^{8}$ Geology \& Geochemistry Research Cluster, Faculty of Science, Vrije Universiteit, De Boelelaan 1085, 1081 HV Amsterdam, The Netherlands.

Received: 16 September 2019 Accepted: 2 December 2019

Published online: 11 December 2019

\section{References}

1. Wadum J, Hoppenbrouwers R, van der Struick L. Vermeer illuminated. Conservation, restoration and research. Wormer: V + K Publishing/Inmerc; 1994.

2. Wadum J. Contours of Vermeer. In: Gaskell I, Jonker M, editors. Vermeer studies: studies in the history of art 55. Washington/New Haven and London: National Gallery of Art/Yale University Press; 1998. p. 201-23. 
3. Broos B, Suchtelen A. Portraits in the Mauritshuis 1430-1790. The Hague/ Zwolle: Royal picture gallery Mauritshuis/Waanders Publishers; 2004.

4. Vandivere A, van Loon A, Callewaert T, Haswell R, Proaño Gaibor AN, van Keulen H, Leonhardt E, Dik J. Fading into the background: the dark space surrounding Vermeer's Girl with a Pearl Earring. Herit Sci. 2019;7:69. https ://doi.org/10.1186/s40494-019-0311-9.

5. Liedtke W. Dutch paintings in The Metropolitan Museum of Art. New York: The Metropolitan Museum of Art/New Haven and London: Yale University Press; 2007. vol. 1, p. ix-x; vol. 2, p. 888-93, no. 205, colorpl. 205.

6. Wheelock AK Jr, Broos B. Catalogue \#15 Girl with a Pearl Earring. In: Wheelock Jr AK, editor. Johannes Vermeer, exhibition catalogue. Washington/ The Hague/New Haven: National Gallery of Art/Mauritshuis/Yale University Press; 1995. p. 166-9.

7. Costaras N. A study of the materials and techniques of Johannes Vermeer. In: Gaskell I, Jonker M, editors. Vermeer studies: studies in the history of art 55. Washington/New Haven and London: National Gallery of Art/Yale University Press; 1998. p. 145-68.

8. Behault S. Blue-hued scattering in Flemish Baroque and Dutch Golden Age paintings. In: Simone G, Hardeberg JY, Farup I, Davis A, Parraman C, editors. Color-Coded: The CREATE 2010 conference. Gjøvik: Norway; 2010. p. 86-90.

9. Vermeer's palette. Vermeer and technique [Internet]. 2013. https://www. nationalgallery.org.uk/paintings/research/meaning-of-making/verme er-and-technique/vermeers-palette. Accessed 29 Aug 2019.

10. Gifford EM, Glinsman LD. Collective style and personal manner: Materials and techniques of high-life genre painting. In: Waiboer AE, Wheelock Jr. AK, Ducos B, Bakker P, Buvelot P. Vermeer and the masters of genre painting: Inspiration and rivalry. New Haven and London: Yale University Press, in association with the National Gallery of Ireland; 2017. p. 65-83.

11. Vandivere A, Wadum J, van den Berg KJ, van Loon A. From 'Vermeer Illuminated' to 'The Girl in the Spotlight': approaches and methodologies for the scientific (re-)examination of Vermeer's Girl with a Pearl Earring. Herit Sci. 2019;7:66. https://doi.org/10.1186/s40494-019-0307-5.

12. Alfeld M, Janssens K, Dik J, de Nolf W, Van der Snickt G. Optimization of mobile scanning macro-XRF systems for the in situ investigation of historical paintings. J Anal Atom Spectrom. 2011;26(5):899-909. https:// doi.org/10.1039/COJA00257G.

13. Delaney JK, Dooley KA, van Loon A, Vandivere A. Mapping the pigment distribution of Vermeer's Girl with a Pearl Earring. Herit Sci. 2019; (in preparation).

14. Groen $\mathrm{K}$, van der Werf I, van den Berg K, Boon J. Scientific examination of Vermeer's "Girl with a Pearl Earring". In: Gaskell I, Jonker M, editors. Vermeer studies: studies in the History of Art 55. Washington/New Haven and London: National Gallery of Art/Yale University Press; 1998. p. 169-84.

15. De Meyer S, Vanmeert F, Vertongen R, van Loon A, Gonzalez V, Delaney J, Dooley K, Dik J, Van der Snickt G, Vandivere A, Janssens K. Macroscopic $X$-ray powder diffraction imaging reveals Vermeer's discriminating use of lead white pigments in Girl with a Pearl Earring. Sci Adv. 2019;5:eaax1975. https://doi.org/10.1126/sciadv.aax1975.

16. Gettens RJ, Kühn H, Chase WT. Lead white. In: Roy A, editor. Artists' pigments, a handbook of their history and characteristics, vol. 2. Washington/New York: National Gallery of Art/Oxford University Press; 1993. p. 67-81.

17. Gonzalez V, Wallez G, Calligaro T, Cotte M, De NolfW, Eveno M, Ravaud E, Menu M. Synchrotron-based high angle resolution and high lateral resolution X-ray diffraction: revealing lead white pigment qualities in Old Masters paintings. Anal Chem. 2017;89(24):13203-11.

18. Stols-Witlox M. "The heaviest and the whitest": lead white quality in north western European documentary sources, 1400-1900. In: Spring M, editor. Studying Old Master paintings: technology and practice. London: Archetype Publications; 2011. p. 284-94.

19. Stols-Witlox M, Megens L, Carlyle L. "To prepare white excellent...": reconstructions investigating the influence of washing, grinding and decanting of stack-process lead white on pigment composition and particle size. In: Eyb-Green S, Townsend JH, Clark M, Nadolny J, Kroustallis S, editors. The artist's process: technology and interpretation. London: Archetype Publications; 2012. p. 112-29.

20. Albrecht MI. 'Klein maar fijn', lead white in fine particle size. Master thesis Conservation and Restoration. Amsterdam: University of Amsterdam; 2012.
21. Albrecht MI, Stols-Witlox M. Small is beautiful: lead white in fine particle size. In: Wallert A, editor. Painting techniques: history, materials and studio practice. Amsterdam: Rijksmuseum; 2013. p. 133-7.

22. Gonzalez V, Gourier D, Calligaro T, Toussaint K, Wallez G, Menu M. Revealing the origin and history of lead-white pigments by their photoluminescence properties. Anal Chem. 2017;89(5):2909-18.

23. Polkownik C. Lead white: how variations in the crystalline ratios influence the optical and handling properties of oil paint. Hamilton Kerr Inst Bull. 2018:7:59-68.

24. Faure G. Principle of isotopes geology. New York: Wiley; 1977.

25. Fabian D, Fortunato G. Tracing white: a study of lead white pigments found in seventeenth-century paintings using high precision lead isotope abundance ratios. In: Kirby J, Nash S, Cannon J, editors. Trade in artists' materials: markets and commerce in Europe to 1700. London: Archetype Publications; 2010. p. 426-43.

26. Wadum J, Costaras N. Johannes Vermeer's Girl with a Pearl Earring De- \& Re-Restored. In: Restauration, Dé-Restauration, Re-Restauration..., Preprints of ARAAFU's 4th international symposium; 1995 Oct 5-7; Paris.

27. Saunders D, Kirby J. Light-induced color changes in red and yellow lake pigments. National Gallery Technical Bulletin. 1994;15:79-97. https:// www.nationalgallery.org.uk/technical-bulletin/saunders_kirby 1994.

28. Noble P, van Loon A, Van der Snickt G, Janssens K, Alfeld M, Dik J. The development of new imaging techniques for the study and interpretation of late Rembrandt paintings. In: Bridgland J, editor. Preprints ICOM committee for conservation 17th triennial meeting, Melbourne, 15-19 September 2014. Paris: International Council of Museums; 2014.

29. Gifford EM. Painting light: recent observations on Vermeer's technique. In: Gaskell I, Jonker M, editors. Vermeer studies: studies in the history of art 55. Washington/New Haven and London: National Gallery of Art/Yale University Press; 1998. p. 185-200.

30. Van Suchtelen A, Buvelot Q. Genre paintings in the Mauritshuis. The Hague/Zwolle: Mauritshuis/Waanders Publishers; 2016.

31. Vandivere A, van Loon A, Dooley KA, Haswell R, Erdmann RG, Leonhardt E, Delaney JK. Revealing the painterly technique beneath the surface of Vermeer's Girl with a Pearl Earring using macro- and microscale imaging. Herit Sci. 2019;7:64. https://doi.org/10.1186/s40494-019-0308-4.

32. Howard M. Office treasures: seeing Vermeer. [Internet]. 2013 Feb 8. https ://now.tufts.edu/articles/office-treasures-seeing-vermeer. Accessed 29 Aug 2019.

33. Elkhuizen WS, Callewaert TWJ, Leonhardt E, Vandivere A, Song Y, Pont SC, Geraedts JMP, Dik J. Comparison of three 3D imaging techniques for paintings, as applied to Vermeer's Girl with a Pearl Earring. Herit Sci. 2019;7:89. https://doi.org/10.1186/s40494-019-0331-5.

34. De Meyer S, Vanmeert F, Vertongen $R$, van Loon A, Gonzalez V, Dik J, Van der Snickt G, Vandivere A, Janssens K. Imaging secondary reaction products at the surface of Vermeer's Girl with a Pearl Earring by means of in situ macro X-ray powder diffraction scanning. Herit Sci. 2019;7:67. https://doi. org/10.1186/s40494-019-0309-3.

35. Derrick MR, Stulik D, Landry JM. Infrared spectroscopy in conservation science. Los Angeles: The Getty Conservation Institute; 1999. p. 117.

36. Van der Weerd J, van Loon A, Boon JJ. FTIR Studies of the effect of pigments on the aging of the oil medium. Stud Conserv. 2005;50(1):1-20.

37. Boon JJ, Oberthaler E. Mechanical weakness and chemical reactivity observed in the paint structure and surface of The Art of Painting by Vermeer. In: Haag S, Oberthaler E, Penot S, editors. Vermeer, die Malkunst - Spurensicherung an einem Meisterwerk: Ausstellungskatalog des Kunsthistorischen Museums Wien. Vienna: Residenz Verlag; 2010. p. 235-253, 328-335.

38. D'imporzano P, Keune K, Koornneef JM, Hermens E, Noble P, van Zuilen K, Davies GR. A micro-invasive method for studying lead isotopes in paintings. Submitted to Archeometry.

39. Harley RD. Artists' pigments c.1600-1835. 2nd ed. London: Butterworths; 1982. p. 166-72.

40. Levy-van Halm K. Where did Vermeer buy his painting materials? Theory and practice. In: Gaskel I, Jonker M, editors. Vermeer studies: studies in the history of art 55. Washington/New Haven and London: National Gallery of Art/Yale University Press; 1998. p. 137-44.

41. Van Loon A, Noble P, Boon JJ. White hazes and surface crusts in Rembrandt's Homer and related paintings. In: Bridgland J, editor. ICOM Committee for Conservation 16th Triennial Meeting, Lisbon, 19-23 September 2011. Almada: Critério-Produção Gráfica Lda (CD-ROM). 
42. Price SWT, van Loon A, Keune K, Parsons AD, Murray C, Beale AM, Mosselmans JFW. Unravelling the spatial dependency of the complex solid-state chemistry of $\mathrm{Pb}$ in a paint micro-sample from Rembrandt's Homer using XRD-CT. Chem Commun. 2019;55(13):1931-4. https://doi. org/10.1039/c8cc09705d.

43. Keune K, van Loon A, Boon JJ. SEM backscattered-electron images of paint cross sections as information source for the presence of the lead white pigment and lead-related degradation and migration phenomena in oil paintings. Microsc Microanal. 2011;17(5):696-701. https://doi. org/10.1017/S1431927610094444.

44. Noble P, van Loon A, Boon JJ. Chemical changes in old master paintings II: darkening due to increased transparency as a result of metal soap formation. In: Verger I, editor. Preprints ICOM committee for conservation 14th triennial meeting, The Hague, 12-16 September 2005, vol. 1. London: James and James; 2005. p. 496-503.

45. Noble P, van Loon A, Boon JJ. Selective darkening of ground layers associated with the wood grain in 17th-century panel paintings. In: Townsend J, Doherty T, Heydenreich G, Ridge J, editors. Preparation for painting, the artist's choice and its consequences. London: Archetype Publications Ltd; 2008. p. 68-78.

46. Van Loon A. Darkening as a result of increased transparency in 17 thC oil paintings. In: Color changes and chemical reactivity in seventeenthcentury oil paintings, PhD dissertation University of Amsterdam, Molart Series (14), AMOLF, Amsterdam. 2008; p. 206-39. http://www.amolf.nl/ publications.

47. Alfeld M, Vaz Pedroso J, Van Eikema Hommes M, Van der Snickt G, Tauber G, Blaas J, Haschke M, Erler K, Dik J, Janssens K. A mobile instrument for in situ scanning macro-XRF investigation of historical paintings. J Anal Atom Spectrom. 2013;28(5):760-7. https://doi.org/10.1039/c3ja30341a.

48. Alfeld M, Janssens K. Strategies for processing mega-pixel X-ray fluorescence hyperspectral data: a case study on a version of Caravaggio's painting Supper at Emmaus. J Anal Atom Spectrom. 2015;30(3):777-89. https://doi.org/10.1039/c4ja00387j.

49. Delaney JK, Thoury M, Zeibel JG, Ricciardi P, Morales KM, Dooley KA. Visible and infrared imaging spectroscopy of paintings and improved reflectography. Herit Sci. 2016;4:6. https://doi.org/10.1186/s40494-016-0075-4.

50. Conover DM, Delaney JK, Loew MH. Automatic registration and mosaicking of technical images of old master paintings. Appl Phys A. 2015;119(4):1567-75. https://doi.org/10.1007/s00339-015-9140-1.

51. Van Loon A, Keune K, Boon JJ. Improving the surface quality of paint cross-sections for imaging analytical studies with specular reflection FTIR and static-SIMS. In: Proceedings of Art'05, conference on nondestructive testing and microanalysis for the diagnostics and conservation of the cultural and environmental heritage, Lecce, 15-19 May 2005.

52. Giannuzzi LA, Drown JL, Brown SR, Irwin RB, Stevie FA. Focused ion beam milling and micromanipulation lift-out for site specific cross-section TEM specimen preparation. Mater Res Symp Proc. 1997:480:19-27. https://doi. org/10.1557/PROC-480-19.

\section{Publisher's Note}

Springer Nature remains neutral with regard to jurisdictional claims in published maps and institutional affiliations.

\section{Submit your manuscript to a SpringerOpen ${ }^{\circ}$ journal and benefit from:}

- Convenient online submission

- Rigorous peer review

- Open access: articles freely available online

- High visibility within the field

- Retaining the copyright to your article

Submit your next manuscript at $\boldsymbol{\nabla}$ springeropen.com 